\title{
COLORADOSCHOOLOFMINES
}

EARTH・ENERGY•ENVIRONMENT

Division OF ECONOMICS AND BUSINESS

WORKING PAPER SERIES

\section{Variable Long-Term Trends in Mineral Prices: The Ongoing Tug-of-War between Exploration, Depletion, and Technological Change}

John T. Cuddington

Grant Nülle

\author{
Working Paper 2013-02 \\ http://econbus.mines. edu/working-papers/wp201302.pdf \\ Colorado School of Mines \\ Division of Economics and Business \\ 1500 Illinois Street \\ Golden, CO 80401 \\ May 2013
}

(C) 2013 by the listed authors. All rights reserved. 
Colorado School of Mines

Division of Economics and Business

Working Paper No. 2013-02

May 2013

Title:

Variable Long-Term Trends in Mineral Prices: The Ongoing Tug-of-War between Exploration, Depletion, and Technological Change*

Author(s):

John T. Cuddington

William Jesse Coulter Professor of Mineral Economics

Division of Economics and Business

Colorado School of Mines

Golden, CO 80401-1887

jcudding@mines .edu

Grant Nülle

Division of Economics and Business

Colorado School of Mines

Golden, CO 80401-1887

gnulle@mymail.mines.edu

\begin{abstract}
This paper explores the use of low-frequency band-pass filters for describing long-run trends in real mineral commodity prices. This approach has the advantage of allowing long-run trends rate to evolve gradually over time, rather than assuming that they are constant (perhaps with occasional structural breaks) over time. This is a flexible way of capturing the ongoing tug of war between exploration, depletion, and technological change.

Over 100 mineral and commodities, stretching back to the late 19th or early 20th century, are considered. The variety of LR trends is astonishing, but very few increase monotonically, contrary to the prediction of the basic Hotelling model. Some decline monotonically (as predicted by Prebisch and Singer); some have the U-shaped pattern predicted by Pindyck (1978), Heal (1981) and Slade (1982). Others have changed direction up to three times in the period since 1900. The tug of war continues with exhaustion nowhere in sight.
\end{abstract}

\footnotetext{
*A preliminary version of this paper was Cuddington's keynote presentation at the August 2012 conference on the Economics and Econometrics of Commodity Prices in Rio de Janeiro. The conference was cosponsored by VALE and the Getulio Vargas Foundation. A revised version from the 2013 IMF conference on commodity markets is scheduled for publication in the Journal of International Money and Finance.
} 


\section{Overview}

This paper explores the use of low-frequency band-pass filters for describing long-run trends in more than 100 real mineral commodity prices over more than 100 years. Our statistical approach has the advantage of allowing long-run trend rates to evolve gradually over time, rather than assuming that they are constant (perhaps with occasional structural breaks) over time. This is a flexible way of capturing the ongoing 'tug of war' between exploration, depletion, and technological change. Our objective is to provide a comprehensive description of long-term trends in nonrenewable resource prices, and to compare this description to theoretical predictions in the mineral and energy economics literature.

Measuring the direction and magnitude of trends in the real prices of nonrenewable resources is of considerable interest to financial market participants, mineral and energy producers contemplating long-term investments extractive activities, and policy-makers alike, with wide-ranging implications for producers and consumers of mineral products, and their host governments. Fundamental questions include: (i) Will real prices of at least some non-renewable resources rise dramatically over time, signaling increasing economic scarcity? (ii) Will some non-renewable or 'exhaustible' resource supplies indeed be physically exhausted before they become economically obsolete, or vice versa? Policies and decisions that households, enterprises, and governments undertake concerning resource use will clearly hinge on understanding trends in non-renewable resource prices.

The importance of the availability of non-renewable resources is well summarized by Tilton (2003). He observes that, although extraction and consumption of non- 
renewable resources have occurred since the Stone Age, the pace of exploitation has rapidly accelerated. We have consumed more aluminum, copper, iron and steel, phosphate rock, diamond, sulfur, coal, oil, natural gas, and even sand and gravel during the current century than in all prior centuries combined. Tilton then goes on to discuss a number of underlying causes for this explosion in mineral use:

- Advances in technology allow extraction... at lower and lower cost. [Shifts mineral supply curves down]

- Advances in technology also permit new and better mineral commodities serving a range of needs. [Shifts mineral demand curves out/up]

- Rapidly rising living standards in many parts of the globe are increasing demand across the board for goods and services, including many that use mineral commodities intensively in their production [Shifts the derived demand for minerals out/up]

- Surge in world population means more and more people with needs to satisfy. [Shift the derived demand for mineral in or out depending on the relative mineral intensity of various goods.]

In addition, exploration and extraction technologies have also improved dramatically, as evidenced by the major upheavals occurring in the hydrocarbon sector on account of horizontal drilling and hydraulic fracturing techniques.

In assessing the repercussions from ongoing consumption and exploitation of nonrenewables, real prices serve as the key measure of economic scarcity - in part because in-situ reserve values and marginal production costs are heterogeneous, difficult to 
measure, and expensive to obtain from industry data sources. ${ }^{1}$ Periods of sharply rising real resource prices garner intense interest from policy makers, who seek to understand perceived 'shortages' (physical deprivations of resources in the short run), as well as geopolitical threats involving access to resource-intensive regions. Their responses to real price spikes vary in intensity and reach, from commissioning official studies to promulgating new policies. Examples of the former include the "Paley Commission" concerning the sufficiency of exhaustible resources during the Korean War, similar endeavors following the oil price shocks of the 1970s, and recent legislative inquiries into the availability of "rare earth" minerals in the United States and Europe. Policy interventions include the imposition of oil price controls and rationing of gasoline supplies in the 1970s and stockpiling in the case of the U.S. Strategic Petroleum Reserve and National Defense Stockpile.

By contrast, epochs when primary commodities' prices (relative to those in the manufacturing sector) exhibit a secular declining trend give rise to wide-ranging reorientation of nations' economic policies. The widespread adoption of “importsubstitution" policies in South America, for example, was designed to prevent excessive reliance on primary commodity exports.

The next section of this paper commences with a brief overview of the theoretical and empirical literature concerning long-run price trends of non-renewable resources. Section III describes our long-span data and the band-pass methodology used to evaluate real price trends. Sections IV through VIII present our empirical findings and comment

\footnotetext{
${ }^{1}$ See Brown \& Field (1978) and Tilton (2003) for discussions concerning the drawbacks to the alternative economic measures of resource scarcity.
} 
on how well they match various theoretical predictions. The paper ends with some concluding remarks. 


\section{A Selective Review of Literature on Long-term Mineral Price Trends}

Measuring trends in the real price of resources allows us to assess various economic theories, including the classic Hotelling (1931) model of non-renewable resource prices, and generalizations and extensions of that model by Stiglitz (1976), Pindyck (1978), Hartwick (1980), Heal (1981) and Slade (1982), and many others. The benchmark Hotelling model predicts that the shadow prices of in-situ resources should rise at the rate of interest. (If marginal extraction costs were zero, prices of mineral products would also rise at this rate.)

Subsequent authors, including Pindyck (1978), Levhari and Pindyck (1981), and Slade (1982), focus on the countervailing forces of declining resource quality, technological innovation, exploration, and recycling. In these models, a U-shaped price path emerges with prices initially falling but then later rising as scarcity overpowers the downward pressure that technological change exerts on prices.

In addition to the Hotelling literature, there is an important strand of economic development literature that examines the price paths of mineral and energy commodities, namely the Prebisch-Singer hypothesis. Prebisch (1950) and Singer (1950) anticipate there will be a negative secular trend in the relative prices of primary commodities ${ }^{2}$ in terms of manufactured products, diminishing the terms of trade of commodity-intensive exporters over time. When combined with a slow rate of technical progress in the primary sector relative to manufactures, the Prebisch-Singer hypothesis provides a plausible

\footnotetext{
2 Prebisch-Singer's analysis pertained to primary commodities (to include food and non-food agricultural products) in general, not just nonrenewable resources.
} 
explanation as to why countries specializing in commodity production and export lag behind the industrialized world.

Empirical investigations of the Prebisch-Singer hypothesis include Grilli and Yang (1988), Cuddington and Urzúa (1989), Powell (1991), Kim et al (2003),

Cuddington et al (2007), and Harvey et al (2010).

The Hotelling (1931) 'benchmark' theory of nonrenewable resources presents the optimal control problem faced by an owner of an exhaustible resource stock $(\mathrm{R})$ sold in a competitive market. Producers choose the extraction level in each period to maximize the discounted profit steam:

$$
V_{0}=\int_{0}^{\infty}\left[(p(t) q(t)-C q(t)] e^{-r t} d t\right.
$$

subject to the constraints concerning production and reserves:

$$
q(t)>0, R(t)>0, \dot{R}=-q(t)
$$

where $\mathrm{r}$ is the market discount rate, $\mathrm{p}(\mathrm{t})$ represents price, and $\mathrm{q}(\mathrm{t})$ represents quantity of resource. The cost function, $\mathrm{C}$, is a constant unit extraction cost. Hotelling demonstrated that in a competitive market, the market price of an extracted resource should exceed the marginal extraction cost by an amount equal to the shadow price of the reserve being used - the so-called user cost. Moreover the user cost should rise over time at a rate equal to the interest rate. This is the famous "Hotelling Rule." Dasgupta and Heal (1979, p. 156) note, "It would not be an exaggeration to regard [this equation] as the fundamental principle of exhaustible resources."

Although the basic Hotelling model yields intuitive results and an appropriate framework for evaluating the optimal extraction of exhaustible resources over time and 
the concomitant price path, the benchmark model contains several limiting assumptions, as noted by Gaudet (2007). First, marginal costs are assumed unvarying, independent of current production or remaining reserves, and impervious to technological progress. Second, the stock of reserves is fixed and uniform in grade, obviating the possibility of exploration and discovery of additional reserves. Third, extraction capacity is not at all limited by the large irreversible investment of capital equipment that is required to bring mineral production online. Some 80 years since Hotelling's seminal work, scores of extensions and generalizations of the Hotelling model have appeared.

Long-span mineral price data are readily available and have been examined by many researchers in both the resource economics (Hotelling) and economic development (Prebisch-Singer) literatures. The 'game' is to get the longest data span possible and to apply robust time series techniques to these data. Classic examples of this approach include Barnett and Morse (1963), where the authors developed scarcity indexes based on aggregated labor and capital cost per unit of mineral, forestry, and agriculture outputs to test if resource exhaustion was indeed a threat. With a dataset from 1887 through 1957 , the authors found no significant trend (either positive or negative) for any of the aggregated output categories. Similarly, Smith (1979) performed regressions on timeseries data running from 1900 to 1973, postulating a linear relationship between price and time. He concluded that time coefficients for the mineral, forestry, or agriculture aggregated commodity indices were generally not stable over time. He found that timetrend coefficients appeared to become less negative over time, and, in some instances, actually increased, with only forestry products showing a positive and statistically significant positive time trend. 
In an effort to capture the countervailing effects of declining ore grade and costsaving technological progress on resource prices, Slade (1982) introduced a quadratic time trend term, thereby generalizing the basic linear time trend model. Her model assumes that marginal cost is constant for a given grade and state of technology, and that the rate of change of price is equal to the rate of change of marginal cost due to changes in technology plus the discount rate times the rental rate. If the rate of technical change is sufficiently large, then the decreasing rate of marginal cost will eclipse the impact of the rent, and prices will correspondingly fall. However, if the change in marginal cost is negative but approaching zero, then prices will increase - implying a U-shaped price path. Taking price series for eleven separate exhaustible mineral and energy commodities and an aggregate index of the eleven over the period 1870-1978, Slade found that for a quadratic time trend specification all eleven minerals and the aggregate index exhibited negative linear time trend and positive quadratic trend coefficients. All but two of the linear coefficients were statistically significant at the 90 percent confidence level, and all but one of the quadratic trend coefficients was statistically significant at the 90 percent confidence level. The empirical results gave credence to the U-shaped price path anticipated by Slade's theoretical model of resource prices.

Much of the literature focuses on estimating either Trend Stationary (TS) or Difference Stationary (DS) specifications in order to estimate the constant long-term trend (albeit with the possible search for occasional breaks). The overall conclusion is that any trend is small and difficult to estimate precisely given the significant year-to- 
year volatility in the price series. See, e.g., Smith (1979) Cashin and McDermott (2001), and Cuddington et al (2008). ${ }^{3}$

\section{Extracting Variable Long-run Trends using Band-Pass Filters}

Nonrenewable prices in the long run presumably reflect the tug-of-war between exploration, depletion and technological change as modeled by Slade (1982) and explicated by Tilton (2003). There is no reason to expect that balance among these forces should remain constant over the longest available data span, as much of the univariate time series modeling assumes. This notion is not new in the resource economics literature. For example, Barnett and Morse (1963) and Smith (1979) pointed to the presence of alternating trends of rising and falling prices of non-renewable commodity prices over the timespans 1870 to 1957 and 1900 to 1973, respectively. Tilton (2003, p. 54) summarizes the literature on long-term price trends this way:

History also strongly suggests that the long-run trends in mineral prices... are not fixed. Rather they shift from time to time in response to changes in the pace at which new technology is introduced, in the rate of world economic growth, and in the other underlying determinants of mineral supply and demand. This not only complicates the task of identifying the long-run trends that have prevailed in the past, but cautions against using those trends to predict the future. Because the trends have changed in the past, they presumably can do so as well in the future.

\footnotetext{
${ }^{3}$ Using the quadratic trend model, Berck and Roberts (1996) found U-shaped price paths in trendstationary models, but not with difference stationary models.

Krautkraemer (1998) found prices for many minerals and energy commodities fell during 1980s and 1990s, likely altering the results of Slade (1982).

Concerning the Prebisch-Singer literature, Harvey et al (2010) found, using data series spanning the seventeenth to the twenty-first centuries, a secular, deteriorating trend is a relevant phenomenon for a significant proportion of primary commodities.
} 
It is our belief that empirics on long-term mineral price behavior should allow for variable trends - that is, the gradual evolution in LT trends without constraining the trends to be constant (or u-shaped) over time. Band-pass filters, which decompose an economic time series into trend and cyclical components, provide one way of doing this if our objective is data description and historical analysis, rather than hypothesis testing. Economists have a long-standing interest in decomposing various economic time series into trends and cycles. Empirical economists often use data filters to isolate features of interest and eliminate elements that are a nuisance from the point of view of the theoretical models they are studying.

Explaining how data filters work, Cogley (p. 70) notes: "The starting point is the Cramer representation theorem, ... which provides a basis for decomposing $\mathrm{x}_{\mathrm{t}}$ and its variance by frequency. It is perfectly sensible to speak of long- and short-run variation by identifying the long run with low-frequency components and the short run with highfrequency oscillations.” For economists working in the time (rather than frequency) domain, the cyclical component is a two-sided moving average with infinitely many leads and lags.

Although the 'ideal' filters have infinitely many leads and lags, actual filters necessarily involve lead and lag truncation. Baxter-King (1999) and ChristianoFitzgerald (2003) provide two similar methods for doing this. Actual filters may be symmetric (centered) or asymmetric (uncentered). Symmetric filters have the advantage that they do not cause phase shift in the smoothed series relative to the underlying series. On the other hand, they have the disadvantage that they cannot be calculated all the way to the end of the dataset under investigation. For example, consider a 51-period centered 
moving average. This moving average can't be calculated for the final 25 periods of the dataset. In contrast, asymmetric filters are designed to allow the filtered series to be calculated all the way to both ends of the data set, but invariably involve some phase shift.

Band-pass (BP) filters allow us to extract cyclical components within specified periods (or frequencies) from an economic time series. Through repeated use of the filter with different 'windows,' it is straightforward to decompose any time series into a set of mutually exclusive and completely exhaustive cyclical components that sum to the series itself. In the initial application, Baxter and King (1999) defined business cycle fluctuations as lying in a 'period window' between 6 and 32 quarters. ${ }^{4}$ Using this definition of the business cycle component, they then decompose arbitrary quarterlyfrequency time series $Y_{t}$ into three components:

$$
\begin{aligned}
& Y_{t} \quad Y_{t}(2,6)+Y_{t}(6,32)+Y_{t}(32, \quad) \\
& \text { where } \\
& Y_{t}(2,6)=\text { seasonal component }+ \text { noise } \\
& Y_{t}(6,32)=\text { biz cycle component } \\
& Y_{t}(32, \quad)=\text { trend component }
\end{aligned}
$$

\footnotetext{
${ }^{4}$ Note that the highest-frequency (or shortest period) cycle that can be identified equals 2 times the data frequency.
} 
Parenthetically, this 'trend' defined as cyclical components greater than 32 quarters is not very smooth or trend-like for many macro series.

In another application of band-pass filters, Comin and Gertler (2006) study business cycles and 'medium-term' business cycles using quarterly data. Their trend consists of frequencies in excess of 200 quarters (or 50 years). So their decomposition looks like this:

$$
\begin{aligned}
& Y_{t} \quad Y_{t}(2,32)+Y_{t}(32,200)+Y_{t}(200, \quad) \\
& \text { where } \\
& Y_{t}(2,32)=\text { biz cycle }+ \text { seasonal }+ \text { noise } \\
& Y_{t}(32,200)=\text { medium term cycle } \\
& Y_{t}(200, \quad)=\text { trend }
\end{aligned}
$$

This results in a much smoother long-run trend.

Cuddington-Jerrett (2008) use annual data to decompose the prices for six metals traded on the London Metal Exchange (the 'LME6') into business cycles, intermediate cycles, super cycles, and long-run trend. They use the Baxter-King and ChristianoFitzgerald definition of the business cycle component as 2-8 years, and a 20-70 year window for super cycles as implied by the discussion in Alan Heap's (2005) work. This leaves an intermediate or medium cycle in the gap between eight and twenty years, and trend as the residual of 70 years and beyond. Thus, the Cuddington-Jerrett decomposition is: 


$$
\begin{aligned}
& P_{t} \quad P_{t}(2,8)+P_{t}(8,20)+P_{t}(20,70)+P_{t}(70, \quad) \\
& \text { where } \\
& P_{t}(2,8)=\text { biz cycle } \\
& P_{t}(8,20)=\text { medium cycle } \\
& P_{t}(20,70)=\text { super cycle } \\
& P_{t}(70, \quad)=\text { long run trend }
\end{aligned}
$$

The present paper follows Cuddington and Jerrett by defining the long-term trend as all cyclical components in excess of 70 years denoted $P_{t}(70, \quad)$ using the asymmetric Christiano-Fitzgerald (ACF) filter:

$$
\begin{aligned}
& P_{t} \quad P_{t}(2,70)+P_{t}(70, \quad) \\
& P_{t}(2,70)=\text { 'aggregate' cyclical component } \\
& P_{t}(70, \quad)=\text { long term trend component }
\end{aligned}
$$

A trend defined this way will evolve very gradually over time. It can accommodate series that are stationary, trend stationary or I(1) with or without drift. Our definition of the long-term trend is, of course, somewhat arbitrary. We also considered 50 years, which is the implied LT trend in the Comin-Gertler (2006) paper, for comparative purposes.

Our definition is consistent with various informal notions of the long run. It is longer than the typical capital investment horizon for long-term mining projects. Sillitoe (1995), on the other hand, finds that the time from initial exploration spending to cash flow is 27.5 years for base metals and 29 years for gold projects. 
Less formally, consider the division of a typical individual's life into three broad periods: ages 0-20 are the 'financial unaware;' those in the 35 year span from 20 through, say 55 are 'active investors," and finally those in the age cohort 55-90 are "experienced investors.' This would yield a 'long run' of roughly 70 'aware' years, after which we are all dead, to (mis)quote Keynes!

Before turning to our empirical analysis, we conclude this section with some cautionary remarks about band-pass filters. First, tests of the statistical significance of a specified cyclical component are unavailable (as far as we know). How do we know when/if our cyclical components are statistically or economically significant? Thus, our analysis is best viewed as an exercise in descriptive statistics, not statistical inference. Although data filters are certainly convenient for constructing rough and ready measures of the business cycle or longer cycles, some economists are concerned about the spurious cycle problem. As Cogley (p. 74) notes: "Cogley and Nason (1995) consider what would happen if $x_{t}$ were a random walk with drift. For a random walk, expected growth is constant regardless of whether the level is a local minimum or maximum. Because it lacks the catching-up feature, many economists would say that a random walk is acyclical. Nevertheless, when the Hodrick-Prescott filter is applied to a random walk, a large and persistent cycle emerges. Thus, the Hodrick-Prescott filter can create a business cycle even if no trend reversion is present in the original data. Cogley and Nason call this a spurious cycle. Furthermore, the problem is not unique to the HodrickPrescott filter. Benati (2001), Murray (2003) and Osborn (1995) document similar results for band-pass filters and for other approximations to high-pass filters." (p.74) 
This spurious trend and cycle problem, it should be highlighted, is also an issue when fitting linear, quadratic or higher-order deterministic trend models. We make no effort to resolve these difficult conceptual issues in this paper.

\section{Variable Long-term Trends}

In this paper, long-span data for real prices for a wide variety of minerals are considered. We begin with the Economist Industrial Commodity Price Index, which is available annually from 1862 onward and has been widely used in discussions of longterm commodity price trends. Next, we turn to an analysis of the six major metals on the London Metal Exchange (LME6). Finally, we analyze the entire non-fuel mineral commodity dataset maintained by the U.S. Geological Survey (USGS). The USGS website provides annual data on more than 100 mineral commodities from 1900 (in many cases) through 2010. These include the LME6 utilized in Slade (1982) - - although the data sources and price deflator for the USGS and Slade are different. Concerning the data source discrepancies, Slade primarily relies on Manthy (1978) and other sources featuring U.S. market prices. By contrast the USGS uses "unit value" prices derived from "apparent consumption" that are based on the volume and dollar value of U.S. mineral consumption derived from domestic production, net imports, and changes in inventories. Regarding the deflator, the USGS utilizes the Consumer Price Index (1998=100), while Slade uses the Wholesale Price Index (1967=100), subsequently renamed the Producer Price Index (PPI). Recent studies have indicated that the CPI tends to overstate inflation on the order of $1.1 \%$ per annum (Boskin et al. 1996) due to influences such as substitution bias (consumers substitute away from higher price goods), outlet bias 
(changing preferred places of purchase), and ignoring improvements in product quality over time (Federal Reserve Bank of San Francisco 1997).

Nevertheless, Tilton (2003) and Zellou and Cuddington (2012) show that choice of deflator has little impact on the analysis of long-term price trends - whether the CPI, PPI, or the U.S. Gross Domestic Product Implicit Price deflator is used. This finding extends to use of the United Nations Manufacturers Unit Value (MUV) index, a series reflecting the unit values of manufacturing exports from several industrial countries. ${ }^{5}$ The MUV Index is generally used in analyses of the Prebisch-Singer hypothesis, whereby researchers deflate renewable and non-renewable primary commodity prices by an index of manufacturing unit values. Consequently, this analysis of long-run trends in mineral commodity prices not only speaks directly to the models and empirical predictions of the resource economics strand of the literature (Hotelling), but also the economic development (Prebisch-Singer) literature as well. The graphs in Figure 1 below displays the CPI, GDP Deflator, PPI, and MUV index values from 1990 to 2010 in levels as well as annual percentage changes. What one can see is that the movements of all four deflators tend to move in concert with one another; the MUV is correlated with the other three deflators from a correlation coefficient of .976 and above. The choice of deflator would presumably be a much more important issue if our focus was on short-run fluctuations.

\footnotetext{
${ }^{5}$ See among others Grilli-Yang (1988) and Harvey et al. (2010) where the MUV is used to deflate primary commodity prices.
} 
Figure 1: Comparison of deflator index values, in levels and percentage changes, 1900-2010
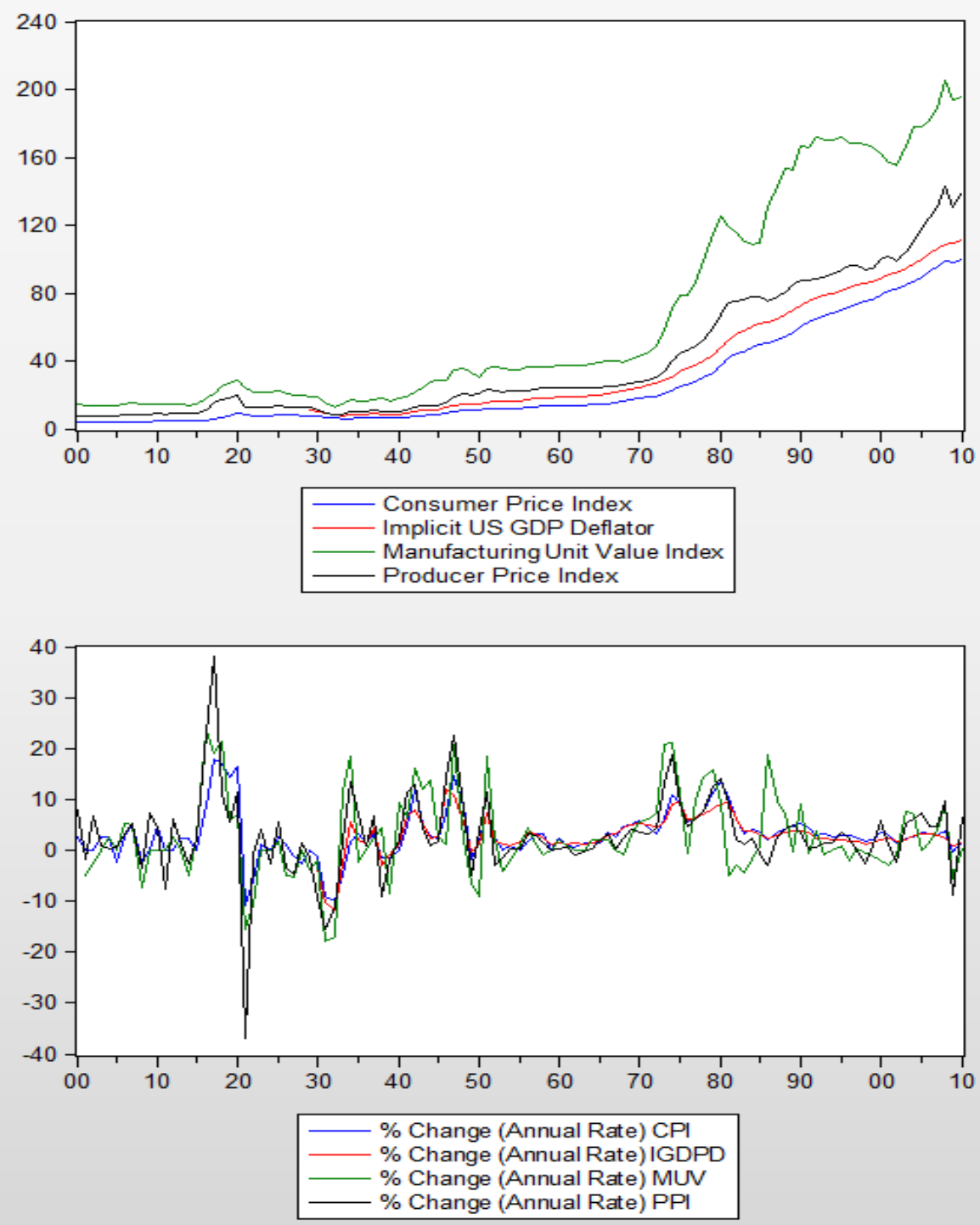

The Economist Industrial Commodity Price Index (EICPI), available annually from 1862 through 2011, serves to illustrate our approach - although not especially appropriate for the study of nonrenewable resources as it includes both renewables and nonrenewables. In particular, agricultural non-food products are included. The index is 
more relevant for examining the Prebisch-Singer hypothesis, which was not limited to nonrenewables. ${ }^{6}$ A word of caution about the EICPI is in order. Both the weights on various commodities and the calculation methods have changed over the past century and a half. Thus, any conclusions based on this index must be interpreted with caution.

Nevertheless, The Economist Index is widely used in empirical research on long-term trends in commodity prices, in part because of its long span. ${ }^{78}$

Table 1: The Economist Industrial Commodity Price Index

\begin{tabular}{|l|c|}
\hline \multicolumn{2}{|l|}{ The Economist Industrials Commodity Price Index } \\
\hline Commodities & Weights \\
\hline Soy oil & 0.2 \\
\hline Coconut oil & 0.6 \\
\hline Palm oil & 1.8 \\
\hline & \\
\hline Wool Australian & 1.4 \\
\hline Wool NZ & 1.4 \\
\hline Cotton & 9.3 \\
\hline Hides & 2.1 \\
\hline Rubber & 9.0 \\
\hline Timber & 4.3 \\
\hline & \\
\hline Copper & 24.2 \\
\hline Lead & 1.7 \\
\hline Zinc & 4.6 \\
\hline Tin & 2.3 \\
\hline Aluminum & 29.5 \\
\hline Nickel & 7.6 \\
\hline Total & $\mathbf{1 0 0 . 0 \%}$ \\
\hline
\end{tabular}

\footnotetext{
6 The broader Economist Commodity Index also includes agricultural food products.

${ }^{7}$ The Economist research staff notes: "Please bear in mind that the index has had different components and methods of calculation over the years, so should be regarded as a guide only." (Private correspondence, July 4, 2012).

${ }^{8}$ See Cashin \& McDermott (2001) as an example. Using the EICPI from 1862-1999, the authors show a downward trend of -1.3 percent per year.
} 
The U.S. Gross Domestic Product Implicit Price deflator is used to calculate real prices in the data provided by The Economist magazine. The Economist also provides a nominal index so one could experiment with different deflators.

Use of a broad index can hide wide variation in trends across commodities. Slade (1982, p. 129) cautions: ${ }^{9}$

"With the exception of lead and zinc, the quadratic curvature for the individual commodities is fairly pronounced. However, prices of the aggregate commodity show no marked trend, either linear or quadratic. Because the minimum point on the price curve occurs early in the period for some commodities (tin and coal) and late in the period for others (aluminum), when the commodities are aggregated, the pronounced curvature disappears. Therefore, general conclusions about natural-resource scarcity cannot be drawn from the aggregate index alone." [Emphasis added]

If one graphs the EICPI using U.S. GDP deflator, along with its long-run trend based on a band-pass filter for components greater than 70 years, one gets Figure 1. Note that the long-run trend defined in this way is negative from the beginning of the dataset in 1862 until 1989 when it turned positive. The EICPI then retained a positive trend through the end of the dataset in 2011.

\footnotetext{
${ }^{9}$ In the same vein, Smith (1979) cautioned against reading too much into long-term trends of aggregate commodity index, citing the varying aggregate composition and the intensity of use of different commodities over long time spans.
} 
Figure 2: The Economist Industrial Commodity Price Index Divided by the U.S. Implicit GDP Deflator (Log Scale)

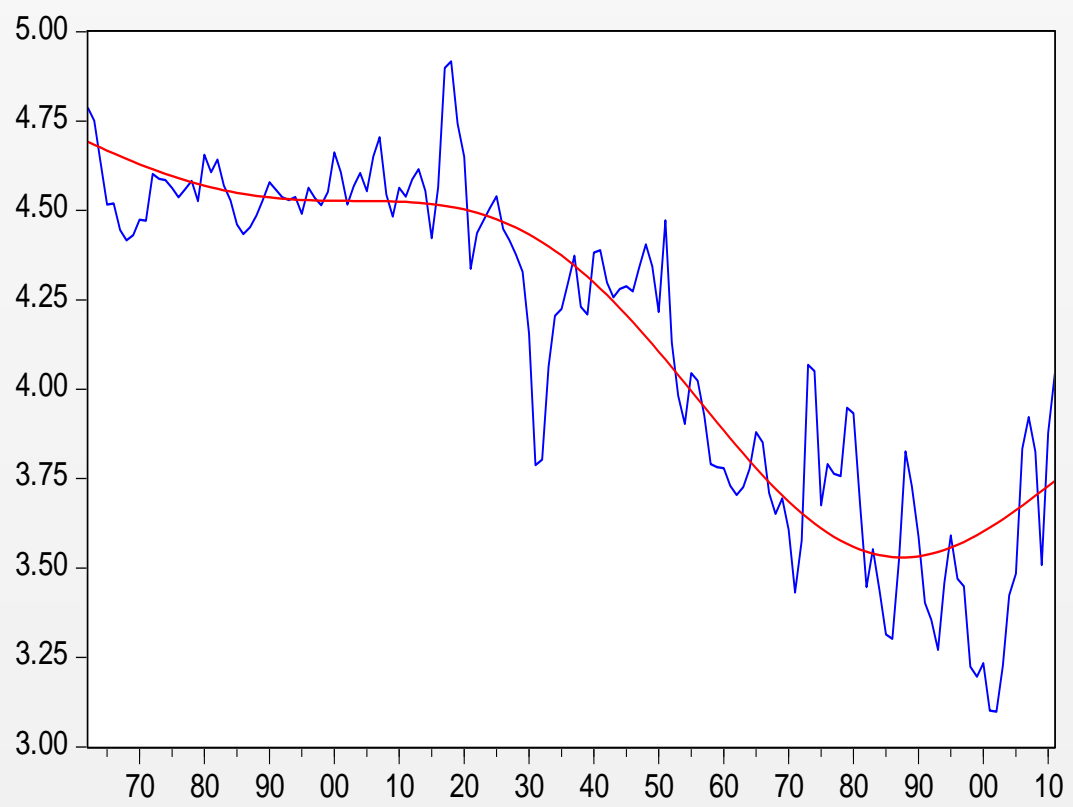

The Figure shows the Real Industrial Commodity Price Index along with its long-run trend defined as the asymmetric Christiano-Fitzgerald Band-Pass Filter of greater than 70 Years. 


\section{Long-Run Trends for the LME6: ACF-Band-Pass Filter Results}

Carrying out a similar analysis for the LME6 yields a wide variety of patterns for their long-term trends. The growth rate in the long-run trend for aluminum is negative over the entire 111-year time span (1900-2010). It never changes direction, although the negative rate of change in the long-run trend varies over time. The long-run price of nickel changes direction once, going from a negative to a positive long-term trend beginning in 1944. Thus, this series is in line with the predictions of Pindyck (1981), Slade (1981) and others.

Tin and zinc, on the other hand, have long-run trends that are initially negative, but later turn positive prior to or on the eve of the Second World War (1924 and 1940, respectively) then both swing negative again beginning in 1971, and finally are on the verge of turning positive again in 2010. This pattern seemingly follows the narrative of world economic growth since the mid $-20^{\text {th }}$ century - expansive economic growth during the postwar rebuilding of Europe and East Asia until world growth, particularly in industrialized countries, stalls in the 1970s only to experience a resurgence in the 1990s.

The patterns for copper and lead are even more complex, as their long-run trends have changed direction three times in the 111-year data sample. Both start the $20^{\text {th }}$ century in a negative trend, with lead shifting to a positive trend in 1926 that persists until 1950. Copper turns positive later -1939- with the positive trend lasting until 1969. Both remain in negative trends until the early 1990 s, when they turn positive within a year of one another - 1994 and 1995 for copper and lead, respectively. 
These results clearly indicate the need to examine the long-term trends in individual mineral commodities, as the number and timing of their turning points varies widely. Consequently, looking at an overall index is of limited value for analysts interested in extracting variable long-run trends.

Figure 2: Long-run Trends in the LME6 as Measured by the Component in Excess of 70 Years
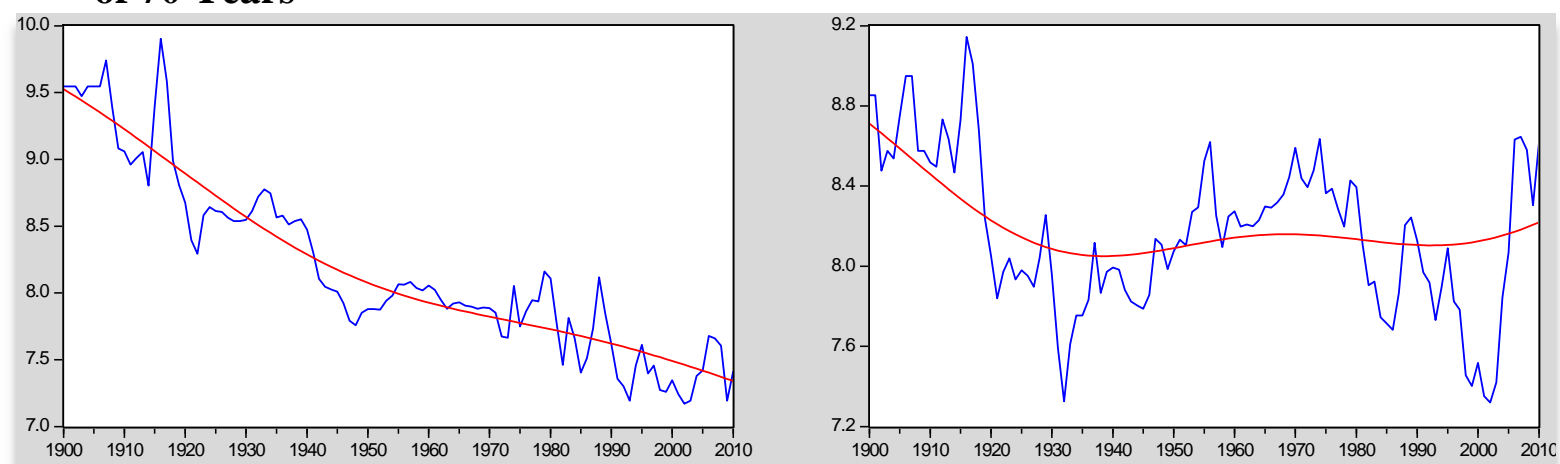

- Aluminum Logged Data

Aluminum Long Term Trend w/ Band Pass Filter - BP(>70) Trend

- Copper Logged Data

_ Copper Long Term Trend w/ Band Pass Filter - BP $(>70)$ Trend
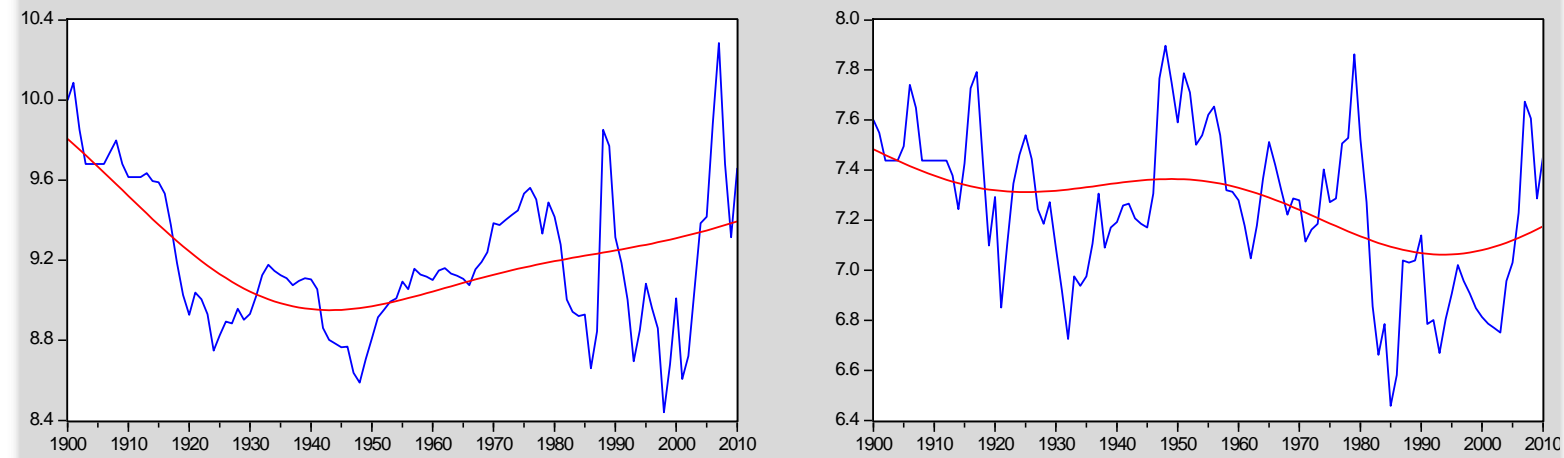

- Nickel Logged Data

Nickel Long Term Trend w/Band Pass Filter - BP(>70) Trend

— Lead Logged Data
- Lead Long Term Trend w/ Band Pass Filter - BP $(>70)$ Trend
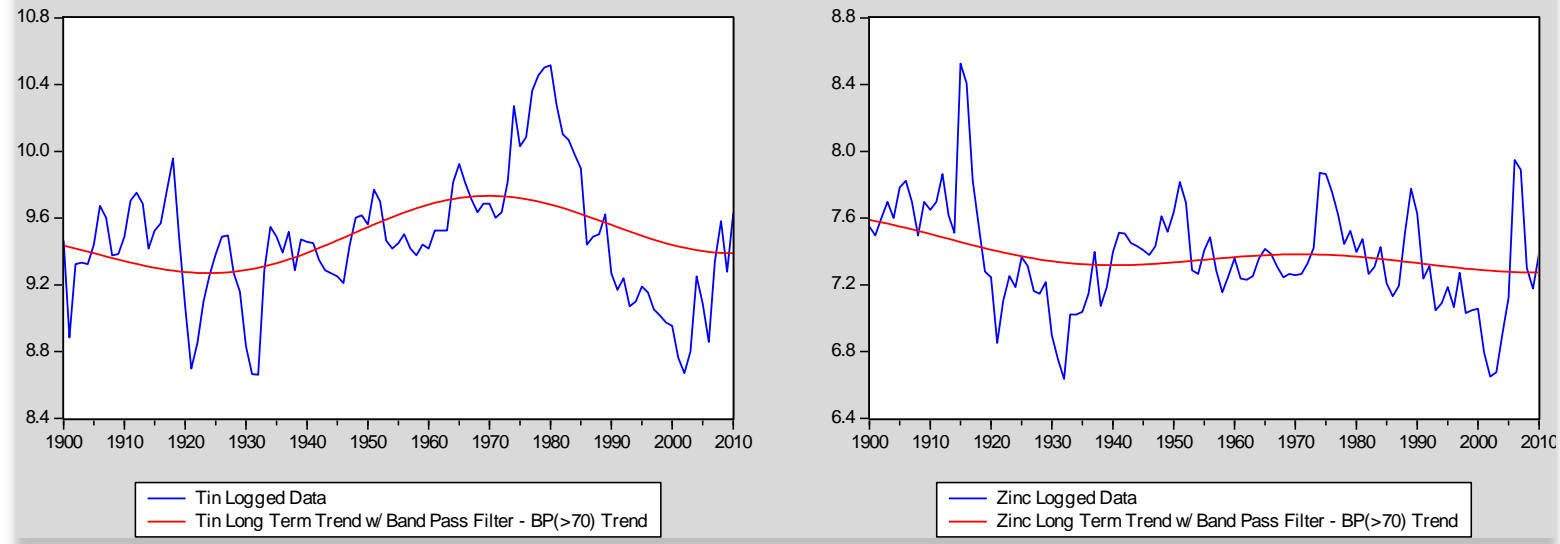
Table 2:

ACF-Band-pass Filter Results on the Growth Rate in the Long-run Trend for the LME6 Metals

\begin{tabular}{|c|c|c|c|c|c|c|}
\hline Mineral & Observations & $\begin{array}{c}\text { Average } \\
\text { Growth Rate in } \\
\text { LR Trend }\end{array}$ & Min & Max & Range & $\begin{array}{c}\text { Number } \\
\text { of Trend } \\
\text { Switches }\end{array}$ \\
\hline Aluminum & 111 & -0.020 & -0.034 & -0.009 & 0.024 & 0 \\
\hline Copper & 111 & -0.004 & -0.026 & 0.013 & 0.039 & 3 \\
\hline Nickel & 111 & -0.004 & -0.029 & 0.009 & 0.039 & 1 \\
\hline Lead & 111 & -0.003 & -0.012 & 0.012 & 0.024 & 3 \\
\hline Tin & 111 & 0.000 & -0.013 & 0.016 & 0.029 & 2 \\
\hline Zinc & 111 & -0.003 & -0.010 & 0.003 & 0.013 & 2 \\
\hline
\end{tabular}

\section{Long-run Trends for the USGS 102 Mineral Commodities}

This section briefly summarizes the growth rates in the long-run trends for all one hundred and two mineral commodities reported by the USGS using annual data that, in many cases, dates back to 1900. As Figure 3 below shows, the trends for many of these minerals have changed, sometimes dramatically, over time. Changes in the sign of the trend, even multiple changes in sign, are common.

Given the large number of mineral commodities considered, our findings are summarized by providing descriptive statistics on the annual long-term growth rate: the mean, minimum, maximum and range. It is interesting to note whether the range includes both positive and negative values, which would imply one or more changes in direction of the LT trend. 
Table 3: USGS Mineral Commodities

\begin{tabular}{|c|c|c|c|c|c|c|}
\hline $\begin{array}{l}\text { ACF-Band-Pass } \\
\text { Filter Results on } \\
\text { Long-run Trend }\end{array}$ & Obs. & $\begin{array}{c}\text { Average } \\
\text { Growth Rate in } \\
\text { Lon-run Trend }\end{array}$ & Min & Max & Range & $\begin{array}{l}\text { Number } \\
\text { of Trend } \\
\text { Switches }\end{array}$ \\
\hline $\begin{array}{c}\text { Abrasives } \\
\text { (manufactured) }\end{array}$ & $1916-2010$ & -0.011 & -0.017 & -0.004 & 0.013 & 0 \\
\hline $\begin{array}{l}\text { Abrasives } \\
\text { (natural) }\end{array}$ & $1914-2010$ & -0.007 & -0.011 & 0.000 & 0.011 & 1 \\
\hline $\begin{array}{c}\text { Abrasive Special } \\
\text { Silica }\end{array}$ & $1914-2007$ & 0.017 & -0.005 & 0.062 & 0.067 & 2 \\
\hline Silver & $1900-2010$ & -0.001 & -0.028 & 0.017 & 0.045 & 1 \\
\hline Aluminum & $1900-2010$ & -0.020 & -0.034 & -0.009 & 0.024 & 0 \\
\hline Aluminum Oxide & $1916-2010$ & -0.022 & -0.054 & 0.001 & 0.055 & 2 \\
\hline Alumina & $1961-2010$ & -0.007 & -0.009 & -0.003 & 0.006 & 0 \\
\hline Arsenic & $1900-2010$ & -0.016 & -0.045 & 0.007 & 0.052 & 2 \\
\hline Asbestos & $1900-2010$ & 0.001 & -0.013 & 0.022 & 0.036 & 2 \\
\hline Gold & $1900-2010$ & 0.007 & -0.010 & 0.023 & 0.033 & 1 \\
\hline Boron & $1900-2010$ & -0.010 & -0.038 & 0.018 & 0.056 & 2 \\
\hline Clay- Ball clay & $1900-2010$ & -0.013 & -0.032 & 0.005 & 0.038 & 2 \\
\hline Barite & $1900-2010$ & -0.003 & -0.011 & 0.006 & 0.017 & 3 \\
\hline Bauxite & $1900-2010$ & -0.011 & -0.028 & 0.005 & 0.033 & 2 \\
\hline Beryllium & $1935-2010$ & -0.024 & -0.049 & -0.009 & 0.040 & 0 \\
\hline Clay-Bentonite & $1930-2010$ & -0.017 & -0.026 & -0.006 & 0.021 & 0 \\
\hline Bismuth & $1900-2010$ & -0.020 & -0.032 & -0.007 & 0.025 & 0 \\
\hline Bromine & $1900-2006$ & -0.025 & -0.037 & -0.006 & 0.031 & 0 \\
\hline Cadmium & $1900-2010$ & -0.025 & -0.068 & 0.016 & 0.085 & 2 \\
\hline Cement & $1900-2010$ & -0.002 & -0.009 & 0.003 & 0.012 & 1 \\
\hline Clays & $1900-2010$ & -0.006 & -0.022 & 0.008 & 0.030 & 3 \\
\hline Cobalt & $1900-2010$ & -0.008 & -0.029 & 0.009 & 0.038 & 2 \\
\hline Chromium & $1900-2010$ & 0.006 & -0.028 & 0.024 & 0.052 & 1 \\
\hline Cesium & $1959-2010$ & 0.045 & -0.042 & 0.099 & 0.141 & 1 \\
\hline Copper & $1900-2010$ & -0.004 & -0.026 & 0.013 & 0.039 & 3 \\
\hline $\begin{array}{l}\text { Diamond } \\
\text { (industrial) }\end{array}$ & $1900-2010$ & -0.061 & -0.117 & -0.021 & 0.096 & 0 \\
\hline Diatomite & $1900-2010$ & 0.005 & -0.009 & 0.019 & 0.028 & 1 \\
\hline Clay Fire clay & $1900-2010$ & -0.001 & -0.008 & 0.004 & 0.012 & 1 \\
\hline Feldspar & $1900-2010$ & -0.002 & -0.013 & 0.003 & 0.016 & 1 \\
\hline Iron ore & $1900-2010$ & 0.003 & -0.017 & 0.016 & 0.033 & 3 \\
\hline $\begin{array}{l}\text { Iron oxide } \\
\text { pigments }\end{array}$ & $1900-2010$ & 0.011 & -0.011 & 0.032 & 0.044 & 1 \\
\hline
\end{tabular}




\begin{tabular}{|c|c|c|c|c|c|c|}
\hline $\begin{array}{l}\text { Iron and steel } \\
\text { scrap }\end{array}$ & $1934-2010$ & 0.001 & -0.015 & 0.022 & 0.037 & 2 \\
\hline $\begin{array}{l}\text { Iron and steel } \\
\text { slag }\end{array}$ & $1942-2010$ & 0.003 & -0.003 & 0.014 & 0.017 & 2 \\
\hline Iron and steel & $1900-1988$ & 0.000 & -0.020 & 0.017 & 0.037 & 2 \\
\hline Fluorspar & $1900-2006$ & 0.003 & -0.019 & 0.024 & 0.044 & 1 \\
\hline $\begin{array}{l}\text { Clay-Fuller's } \\
\text { earth }\end{array}$ & $1900-2010$ & -0.006 & -0.012 & -0.003 & 0.008 & 0 \\
\hline Gallium & $1943-2010$ & -0.070 & -0.090 & -0.036 & 0.053 & 0 \\
\hline $\begin{array}{c}\text { Garnet } \\
\text { (industrial) }\end{array}$ & $1900-2010$ & -0.012 & -0.023 & 0.001 & 0.024 & 2 \\
\hline Germanium & $1945-2010$ & -0.021 & -0.038 & -0.009 & 0.029 & 0 \\
\hline Gemstones & 1929-2010 & -0.062 & -0.099 & -0.018 & 0.081 & 0 \\
\hline $\begin{array}{l}\text { Graphite } \\
\text { (natural) }\end{array}$ & $1900-2010$ & -0.010 & -0.046 & 0.024 & 0.070 & 2 \\
\hline Gypsum & $1900-2010$ & -0.018 & -0.054 & 0.019 & 0.073 & 2 \\
\hline Helium & $1938-2010$ & -0.016 & -0.022 & -0.010 & 0.011 & 0 \\
\hline Hafnium & $1959-2010$ & -0.017 & -0.025 & 0.000 & 0.025 & 1 \\
\hline Mercury & $1900-2010$ & -0.007 & -0.043 & 0.023 & 0.066 & 3 \\
\hline lodine & $1928-2010$ & -0.014 & -0.050 & 0.013 & 0.063 & 2 \\
\hline Indium & $1936-2010$ & -0.038 & -0.110 & 0.015 & 0.125 & 2 \\
\hline Clay-Kaolin & $1900-2010$ & -0.004 & -0.014 & 0.009 & 0.023 & 2 \\
\hline Kyanite & $1934-2010$ & -0.012 & -0.024 & -0.004 & 0.021 & 0 \\
\hline Lithium & $1952-2010$ & -0.025 & -0.039 & -0.016 & 0.023 & 0 \\
\hline Lime & $1904-2010$ & -0.001 & -0.005 & 0.004 & 0.009 & 2 \\
\hline $\begin{array}{l}\text { Magnesium } \\
\text { compounds }\end{array}$ & $1900-2010$ & 0.004 & -0.012 & 0.022 & 0.034 & 3 \\
\hline $\begin{array}{l}\text { Magnesium } \\
\text { metal }\end{array}$ & $1915-2010$ & -0.033 & -0.112 & 0.017 & 0.130 & 2 \\
\hline Mica (sheet) & $1900-2008$ & -0.016 & -0.052 & 0.021 & 0.073 & 2 \\
\hline $\begin{array}{c}\text { Mica (scrap and } \\
\text { flake) }\end{array}$ & $1923-2010$ & -0.006 & -0.023 & 0.015 & 0.039 & 1 \\
\hline Manganese & $1900-2010$ & 0.006 & -0.006 & 0.018 & 0.024 & 2 \\
\hline Molybdenum & $1912-2010$ & 0.007 & -0.012 & 0.027 & 0.039 & 2 \\
\hline $\begin{array}{l}\text { Miscellaneous } \\
\text { clay and shale }\end{array}$ & $1900-2010$ & -0.012 & -0.024 & 0.007 & 0.031 & 1 \\
\hline $\begin{array}{l}\text { Metallic } \\
\text { Abrasives }\end{array}$ & $1916-2010$ & -0.011 & -0.029 & 0.008 & 0.037 & 2 \\
\hline Nitrogen & $1950-2010$ & -0.016 & -0.030 & 0.009 & 0.038 & 1 \\
\hline Sodium sulfate & $1920-2010$ & 0.001 & -0.013 & 0.010 & 0.023 & 2 \\
\hline
\end{tabular}




\begin{tabular}{|c|c|c|c|c|c|c|}
\hline $\begin{array}{c}\text { Niobium } \\
\text { (Columbium) }\end{array}$ & $1964-2000$ & 0.003 & 0.001 & 0.006 & 0.004 & 0 \\
\hline Nickel & $1900-2010$ & -0.004 & -0.029 & 0.009 & 0.039 & 1 \\
\hline Lead & $1900-2010$ & -0.003 & -0.012 & 0.012 & 0.024 & 3 \\
\hline Peat & $1904-2010$ & -0.016 & -0.028 & -0.007 & 0.021 & 0 \\
\hline $\begin{array}{l}\text { Platinum-group } \\
\text { metals }\end{array}$ & $1900-2010$ & 0.005 & -0.025 & 0.052 & 0.077 & 2 \\
\hline Phosphate rock & $1900-2010$ & -0.003 & -0.025 & 0.017 & 0.042 & 3 \\
\hline Potash & $1900-2010$ & -0.015 & -0.048 & 0.022 & 0.070 & 1 \\
\hline Perlite & $1946-2010$ & -0.006 & -0.010 & 0.001 & 0.011 & 1 \\
\hline $\begin{array}{l}\text { Pumice and } \\
\text { pumicite }\end{array}$ & $1902-2010$ & -0.013 & -0.027 & 0.002 & 0.028 & 2 \\
\hline $\begin{array}{l}\text { Quartz crystal } \\
\text { (industrial) }\end{array}$ & 1932-1998 & 0.049 & 0.001 & 0.116 & 0.114 & 0 \\
\hline Rare earths & $1922-2010$ & -0.008 & -0.032 & 0.031 & 0.063 & 1 \\
\hline Rhenium & $1964-2010$ & -0.032 & -0.052 & -0.009 & 0.043 & 0 \\
\hline Sulfur & $1900-2010$ & -0.016 & -0.032 & -0.004 & 0.028 & 0 \\
\hline Salt & $1900-2010$ & -0.005 & -0.012 & -0.001 & 0.011 & 0 \\
\hline Antimony & $1900-2010$ & 0.001 & -0.018 & 0.024 & 0.042 & 3 \\
\hline Silicon Carbide & $1916-2010$ & -0.011 & -0.020 & -0.006 & 0.013 & 0 \\
\hline $\begin{array}{l}\text { Soda ash } \\
\text { (sodium } \\
\text { carbonate) }\end{array}$ & $1920-2010$ & -0.013 & -0.026 & -0.007 & 0.019 & 0 \\
\hline Selenium & $1909-2010$ & -0.010 & -0.038 & 0.021 & 0.059 & 3 \\
\hline Silicon & $1923-2010$ & 0.003 & -0.017 & 0.030 & 0.046 & 2 \\
\hline Tin & $1900-2010$ & 0.000 & -0.013 & 0.016 & 0.029 & 2 \\
\hline $\begin{array}{l}\text { Sand and gravel } \\
\text { (construction) }\end{array}$ & $1902-2010$ & -0.006 & -0.027 & 0.002 & 0.030 & 2 \\
\hline $\begin{array}{l}\text { Sand and gravel } \\
\text { (industrial) }\end{array}$ & $1902-2010$ & 0.003 & -0.008 & 0.010 & 0.018 & 1 \\
\hline Strontium & $1917-2010$ & 0.006 & -0.018 & 0.030 & 0.048 & 2 \\
\hline Steel & $1940-2010$ & 0.002 & -0.004 & 0.010 & 0.014 & 1 \\
\hline Stone (crushed) & $1900-2010$ & 0.003 & -0.020 & 0.029 & 0.049 & 2 \\
\hline $\begin{array}{c}\text { Stone } \\
\text { (dimension) }\end{array}$ & $1900-2010$ & -0.001 & -0.018 & 0.018 & 0.036 & 2 \\
\hline Tantalum & $1964-2010$ & 0.000 & -0.004 & 0.009 & 0.013 & 1 \\
\hline $\begin{array}{c}\text { Talc and } \\
\text { pyrophyllite }\end{array}$ & $1900-2010$ & -0.005 & -0.013 & 0.001 & 0.014 & 2 \\
\hline Tellurium & $1917-2010$ & 0.006 & -0.020 & 0.024 & 0.045 & 1 \\
\hline Thorium & $1951-2010$ & 0.009 & -0.009 & 0.039 & 0.048 & 1 \\
\hline Titanium metal & $1941-2010$ & -0.037 & -0.066 & -0.014 & 0.052 & 0 \\
\hline
\end{tabular}




\begin{tabular}{ccccccc}
\hline $\begin{array}{c}\text { Titanium dioxide } \\
\text { pigment }\end{array}$ & $1939-2010$ & -0.002 & -0.007 & 0.002 & 0.010 & 2 \\
\hline $\begin{array}{c}\text { Titanium scrap } \\
\text { Thallium }\end{array}$ & $1976-2010$ & 0.001 & 0.000 & 0.002 & 0.002 & 2 \\
\hline $\begin{array}{c}\text { Tripoli (Natural } \\
\text { Abrasive) }\end{array}$ & $1942-2010$ & 0.044 & -0.030 & 0.117 & 0.147 & 1 \\
\hline Vanadium & $1910-2010$ & -0.001 & -0.010 & 0.007 & 0.016 & 2 \\
\hline Vermiculite & $1924-2010$ & -0.008 & -0.046 & 0.018 & 0.064 & 2 \\
\hline $\begin{array}{c}\text { Tungsten } \\
\text { Wollastonite }\end{array}$ & $1900-2010$ & 0.003 & -0.022 & 0.025 & 0.048 & 2 \\
\hline $\begin{array}{c}\text { Zinc } \\
\text { Zirconium }\end{array}$ & $1959-2010$ & -0.007 & -0.012 & 0.002 & 0.014 & 1 \\
$\begin{array}{c}\text { mineral } \\
\text { concentrates }\end{array}$ & $1900-2010$ & -0.003 & -0.010 & 0.003 & 0.013 & 2 \\
$\begin{array}{c}\text { Average All } \\
\text { USGS 102 }\end{array}$ & varies & -0.000 & -0.019 & 0.022 & 0.040 & 2 \\
\hline
\end{tabular}

The time plots for all 102 mineral commodities, along with their respective long-run trend components (i.e. BP > 70 years), are shown in the Appendix for interested readers.

The empirical analysis of variable long-run trends in a vast array of mineral commodity prices suggests a wide range of possibilities. Nearly a quarter of the mineral commodities (a total of 24) exhibit no shift in the long-term trend whatsoever; of those, all but two (Niobium, Industrial Quartz Crystal) exhibit incessant negative trends. No mineral commodity exceeded three changes in the sign of the long-run trend.

Some minerals have price trends that average positive over time (Gold, Iron Ore, Silicon) but more (69 or more than two-thirds of the total) have average negative trends (e.g. Aluminum, Bauxite, Industrial Diamonds, Zinc) most of the time. The orientation toward negative trends among the commodity prices tends to be (mildly) supportive of the expectations of the Prebisch-Singer hypothesis. Many of the minerals have long-run trends that vary over time, often switching direction two or three times (51 mineral commodities had long-run trends that have changed direction twice or thrice), but not 
necessarily exhibiting the U-shaped pattern predicted by Pindyck, Heal, and Slade. These commodities include Cobalt, Copper, Iron Ore, Iron and Steel, Molybdenum, Lead, Platinum Group Metals, Tin, and Zinc. Nevertheless some minerals' long-run trends exhibit the U-shaped path, as evidenced by Gold, Nickel, Chromium, Graphite, Rare Earths, and Tellurium.

The wide variety of patterns in the evolution of long-term trends suggests that analysis of an aggregate commodity index should be undertaken with great care, if at all! Variable trends should be analyzed on a commodity-by-commodity basis. Differences in long-run variable trends across commodities presumably reflect the ongoing tug-of-war between exploration, depletion and technological change. Any inquiry and explanation of the relative vitality or weakness of each countervailing force is best carried out at the individual commodity level, but is beyond the scope of this paper.

While the 'stylized facts' obtained in this paper are extremely useful, we highlight a couple of conclusions that should not be drawn from them from the perspective of financial markets and mineral sector long-term capital investments. First, our conclusions regarding trends say nothing about the viability of commodities (or more narrowly mineral commodities) as a financial asset class. Second, the long-term trends alone imply nothing about the expected profitability of investments in exploration activity or long-term investments in resource extraction.

Regarding financial investment in commodities, it is well known that returns from rolling futures contracts can differ greatly from spot returns. See, e.g., Gorton and Rouwenhorst (2006) who provide "some stylized facts about commodity futures and address some commonly raised questions: Can an investment in commodity futures earn 
a positive return when spot commodity prices are falling?" (P.7) They conclude: Yes indeed! "The historical performances of spot commodity prices and collateralized commodity futures returns exhibit large differences." (GR, p.50) As their Table 1 shows, the 'buy and hold' return on spot commodity positions is $4.64 \%$ nominal (with inflation averaging $4.14 \%$ ). The comparable futures return was $11.46 \%$. With periodic rebalancing, the spot returns improve a lot, but are still inferior to futures investments. Investing via futures contracts involves returns from several sources: (i) trends in spot prices, (ii) the roll return on maturing forward contracts, (iii) interest income on fully collateralized positions (assuming 100 margin), and (iv) portfolio rebalancing among the commodities in the index. Note also that spot positions incur storage, shipping, and insurance charges, so spot returns that ignore these considerations are overstated.

Regarding long-term capital investments in mining: Why would anyone invest in an industry where that output price was trending downward and is highly volatile? The response to this is, upon reflection, straightforward. Investments depend on expected profitability. If marginal production costs are falling rapidly due to technological change, the price may be trending downward and yet profits may be high. Selling color televisions may well have remained profitable since their invention in spite of dramatic price reductions (due to rapid technological improvements that have reduced marginal production costs.)

\section{Concluding Remarks}

This paper explores the use of low-frequency band-pass filters for describing long-run trends in more than 100 real mineral commodity prices over more than 100 
years. Our statistical approach has the advantage of allowing long-run trend rates to evolve gradually over time, rather than assuming that they are constant (perhaps with occasional structural breaks) over time. This is a flexible way of capturing the ongoing 'tug of war' between exploration, depletion, and technological change. The objective is to provide a comprehensive description of long-term trends in nonrenewable resource prices, and to compare this description to theoretical predictions in the resource economics and economic development literature.

Measuring the direction and magnitude of trends in the real prices of nonrenewable resources is of considerable interest to financial market participants, mineral and energy producers contemplating long-term investments extractive activities, and policy-makers alike, with wide-ranging implications for producers and consumers of mineral products, and their host governments. Fundamental questions focus on whether real prices of non-renewable resources rise dramatically over time, signaling increasing economic scarcity or the converse, which lends itself to governments eschewing natural resource development and embracing import-substitution led industrial policy. Policies and decisions that households, enterprises, and governments undertake concerning resource use will clearly hinge on understanding trends in non-renewable resource prices.

The variety of LR trends of the motley collection of mineral commodities is astonishing, with few increasing monotonically, contrary to the prediction of the basic Hotelling model. Some decline monotonically (as predicted by Prebisch and Singer), while others exhibit the U-shaped pattern predicted by Pindyck (1978), Heal (1981) and Slade (1982). A great many change the direction of the long-term trend up to three times in the period from 1900 to 2011. 
As such, there is no "general tendency" in the negative or positive direction of long-run mineral commodity price trends; while there are examples therein illustrative of the Hotelling, Prebisch-Singer, and Pindyck/Heal/Slade U-shape models and expectations of long term price trends, none of the seminal models emerge preeminent. The wide variety of patterns in the evolution of long-term trends suggests that analysis of an aggregate commodity index should be undertaken with great care, if at all, and that any analysis of commodity prices is best performed on a commodity-by-commodity basis. More work will have to be done to derive the insights and construct convincing narratives as to why the price paths of particular mineral commodities trend stridently upward, downward, or vacillate sharply between epochs of growth and decline over the long term.

Indeed, the results of the paper are illustrative of the ongoing unremitting 'tug of war' between the countervailing forces of declining resource quality, technological innovation, and exploration, with "exhaustion" of the topic nowhere in sight. 


\section{References}

Baxter, Marianne and Robert G. King. 1999. "Measuring Business Cycles: Approximate Band-Pass Filters for Economic Time Series," The Review of Economics and Statistics 81, 4 (December), 575-593.

Benati, L. 2001. "Band-Pass Filtering, Cointegration, and Business Cycle Analysis," Bank of England Working Paper No 142.

Berck, Peter and Michael Roberts. 1996. "Natural Resource Prices: Will They Ever Turn Up?” Journal of Environmental Economics and Management 31, 65-78.

Brown Jr., Gardner M. and Barry C. Field. 1978. "Implications of Alternative Measures of Natural Resource Scarcity.” Journal of Political Economy 86, 2, 229-43.

Cashin, Paul and C. John McDermott. 2001. "The Long-Run Behavior of Commodity Prices: Small Trends and Big Variability.” IMF Staff Papers 49, 2, 175-199.

Cristiano, L. and T. Fitzgerald. 2003. “The Band Pass Filter," International Economic Review 44, 435-65.

Cogley, Timothy. 2008. "Data Filters," in Steven N. Durlauf and Lawrence E. Blume (eds.) The New Palgrave Dictionary of Economics, $2^{\text {nd }}$ Edition in Eight Volumes, Palgrave MacMillan.

Cogley, T. and J. Nason. 1995. "Effects of the Hodrick-Prescott Filter on Trend and Difference Stationary Time Series: Implications for Business Cycle Research,” Journal of Economic Dynamics and Control 19, 253-78.

Comin, Diego and Mark Gertler. 2006. "Medium-Term Business Cycles." American Economic Review 96, 3, 523-551.

Cuddington, John T., Rodney Ludema and Shamila Jayasuriya. 2007. "Prebisch-Singer Redux," in Daniel Lederman and William F. Maloney (eds.), Natural Resources and Development: Are They a Curse? Are They Destiny? World Bank/Stanford University Press.

Cuddington, John T and Daniel Jerrett. 2008. "Super Cycles in Metals Prices?” IMF Staff Papers 55, 4, 541-565.

Cuddington, John T., and Carlos M. Urzúa. 1989. "Trends and Cycles in the Net Barter Terms of Trade: A New Approach." Economic Journal 99, 396, 426-42.

Gaudet, G. 2007. "Natural Resource Economics Under the Rule of Hotelling," Canadian Journal of Economics 40, 1033-59. 
Gorton, Gary, and K. Geert Rouwenhorst. 2006. "Facts and Fantasies About Commodity Futures." Financial Analysts Journal 62, 2, 47-68.

Grilli, R. E., and M. C. Yang. 1988. "Commodity Prices, Manufactured Goods Prices, and the Terms of Trade of Developing Countries," World Bank Economic Review 2, 1-48.

Hartwick, John. 1975. "Exploitation of Many Deposits of an Exhaustible Resource." Working Paper. Queen's University, Department of Economics.

Harvey, David I., Neil M. Kellard, Jakob B. Madsen, and Mark E. Wohar. 2010. "The Prebisch-Singer Hypothesis: Four Centuries Of Evidence." Review of Economics and Statistics 92, 2, 367-377.

Heal, Geoffrey. 1981. "Scarcity, Efficiency, and Disequilibrium in Resource Markets," Scandinavian Journal of Economics 83, 2, 34-351.

Heal, Geoffrey, and Michael Barrow. 1981. "Empirical Investigation of the Long-term Movement of Resource Prices : A Preliminary Report.” Economics Letters 7, 1, 95-103.

Heap, Alan. 2005. "China - the Engine of a Commodities Super Cycle," New York City: Citigroup Smith Barney.

Hotelling, Harold. 1931. "The Economics of Exhaustible Resources." Journal of Political Economy 39, 2, 137-175.

Kim, T., S. Pfaffenzeller, A. Rayner, and P. Newbold. 2003. "Testing for Linear Trend, with Application to Relative Primary Commodity Prices." Journal of Time Series Analysis 24, 539-551.

Krautkraemer, Jeffrey A. 1998. "Nonrenewable Resource Scarcity." Journal of Economic Literature 36, 4, 2065-2107.

Levhari, David and Robert S. Pindyck. 1981. "The Pricing of Durable Exhaustible Resources." Quarterly Journal of Economics 96, 3, 365-378.

Murray, C. 2003. "Cyclical Properties of Baxter-King Filtered Time Series," Review of Economics and Statistics 85, 472-76.

Osborn, D. 1995. "Moving Average Detrending and the Analysis of Business Cycles," Oxford Bulletin of Economics and Statistics 57, 547-58.

Pindyck, Robert S. 1998. The Long-run Evolution of Energy Prices. Working paper. Massachusetts Institute of Technology (MIT), Sloan School of Management.

Slade, Margaret. 1982. "Trends in Natural-Resource Commodity Prices: An Analysis of the Time Domain," Journal of Environmental Economics and Management 9, 122-137. 
Slade, Margaret and Henry Thille. 2009. "Whither Hotelling: Tests of the Theory of Exhaustible Resources," Annual Review of Resource Economics 1, 239-260.

Smith, V. Kerry. 1979. "Natural Resource Scarcity: A Statistical Analysis," Review of Economics and Statistics 61, 423-427.

Stiglitz, Joseph E. 1976. "Monopoly and the Rate of Extraction of Exhaustible Resources.” American Economic Review 66, 4, 655-61.

Tilton, John E. 2003. On Borrowed Time? Assessing the Threat of Mineral Depletion. Washington, D.C.: Resources for the Future.

Zellou, Abdel, and John T. Cuddington. 2012. "Is There Evidence of Super Cycles in Oil Prices?" in SPE Economics and Management (forthcoming). 
Appendix: Graphs for the 102 USGS Minerals 

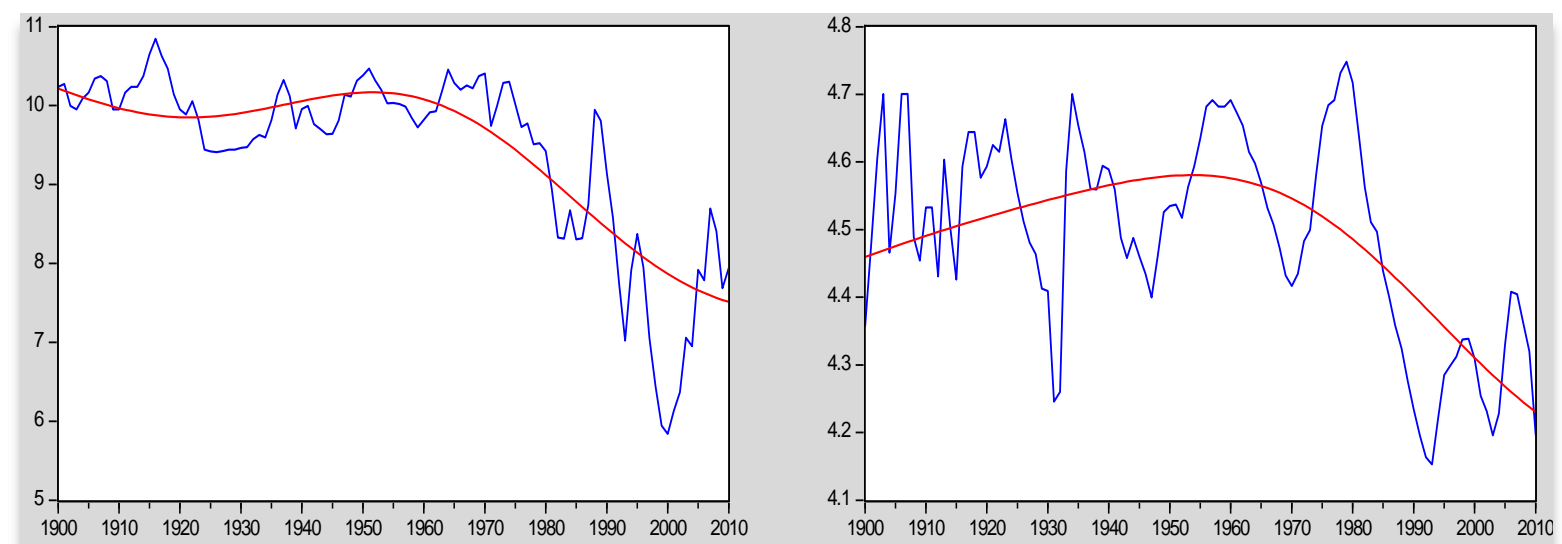

- Cadmium Natural Logs

— Cadmium Long Term Trend w/ Band Pass Filter - BP $(>70)$ Trend
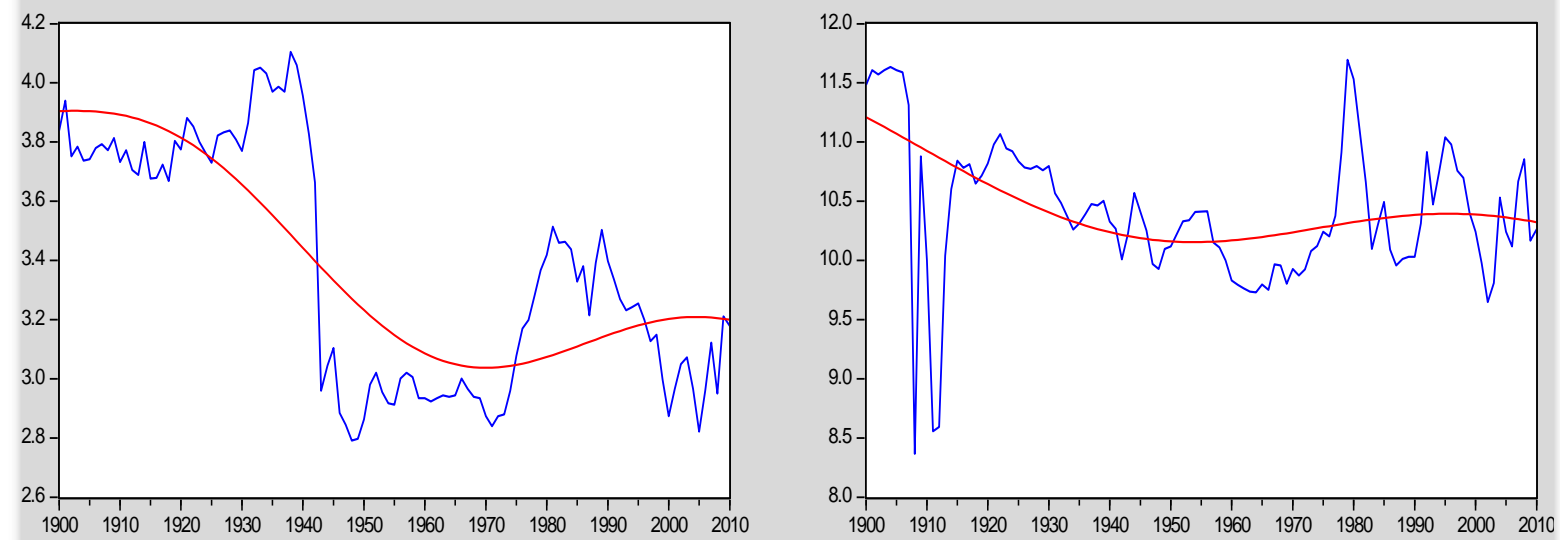

- Clays Natural Logs

_ Clays Long Term Trend w/ Band Pass Filter - BP(>70) Trend
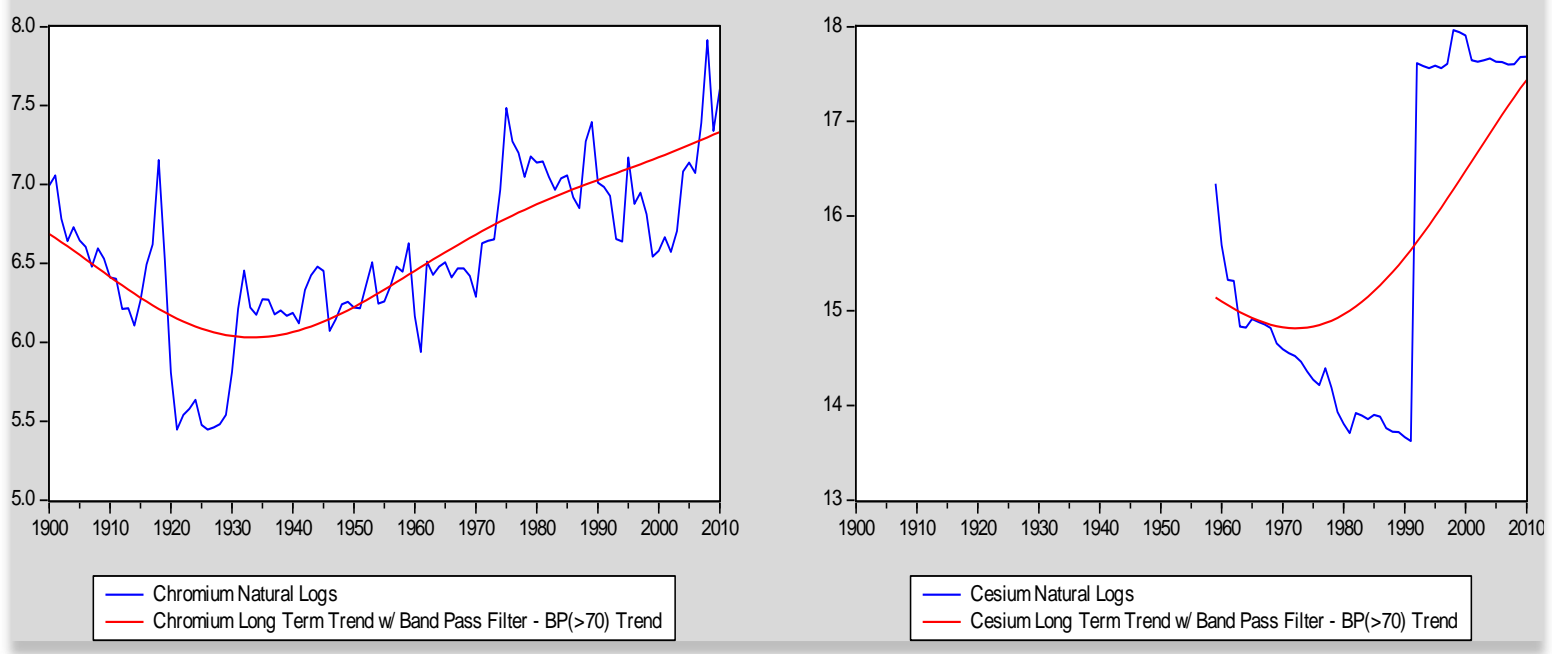

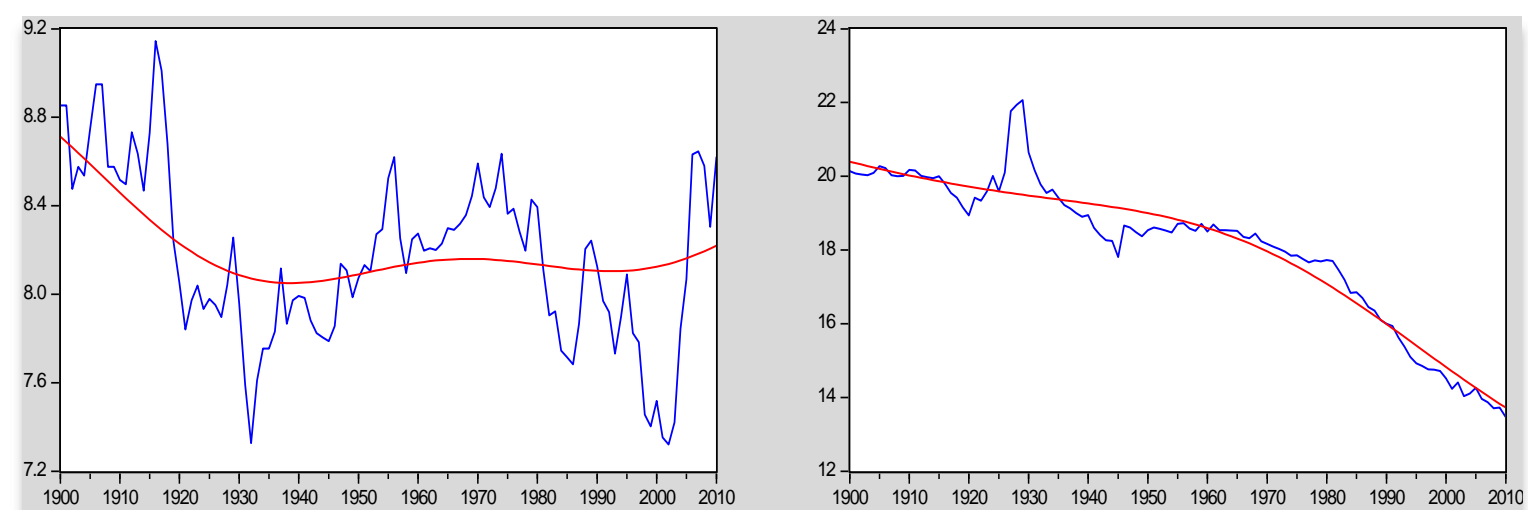

- Copper Natural Logs

- Copper Long Term Trend w/ Band Pass Filter - BP(>70) Trend

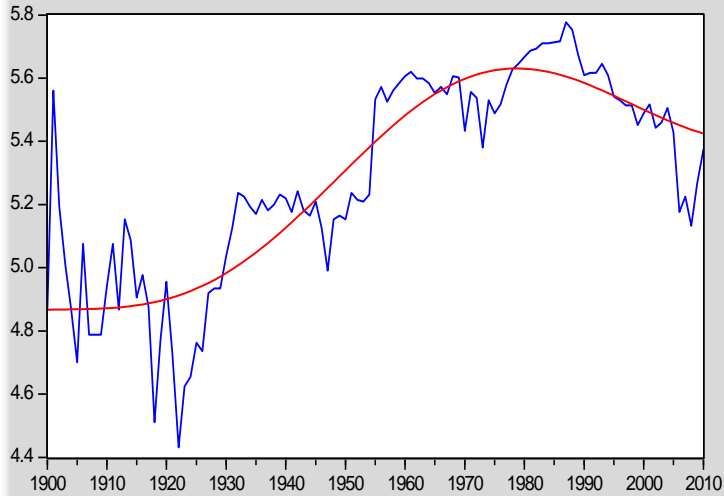

- Diamond (industrial) Natural Logs

- Diamond (industrial) Long Term Trend w/ Band Pass Filter - BP(>70) Trend

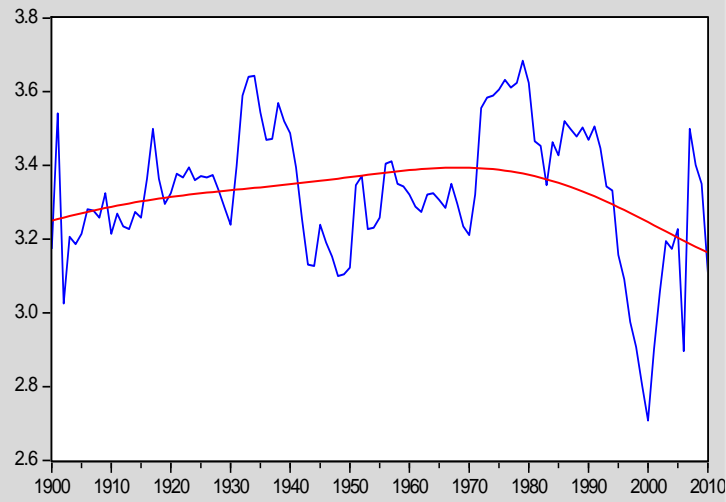

- Diatomite Natural Logs

_ Diatomite Long Term Trend w/ Band Pass Filter - BP( $>70)$ Trend

- Clay Fire clay Natural Logs

_ Clay Fire clay Long Term Trend w/ Band Pass Filter - BP( $>70)$ Trend
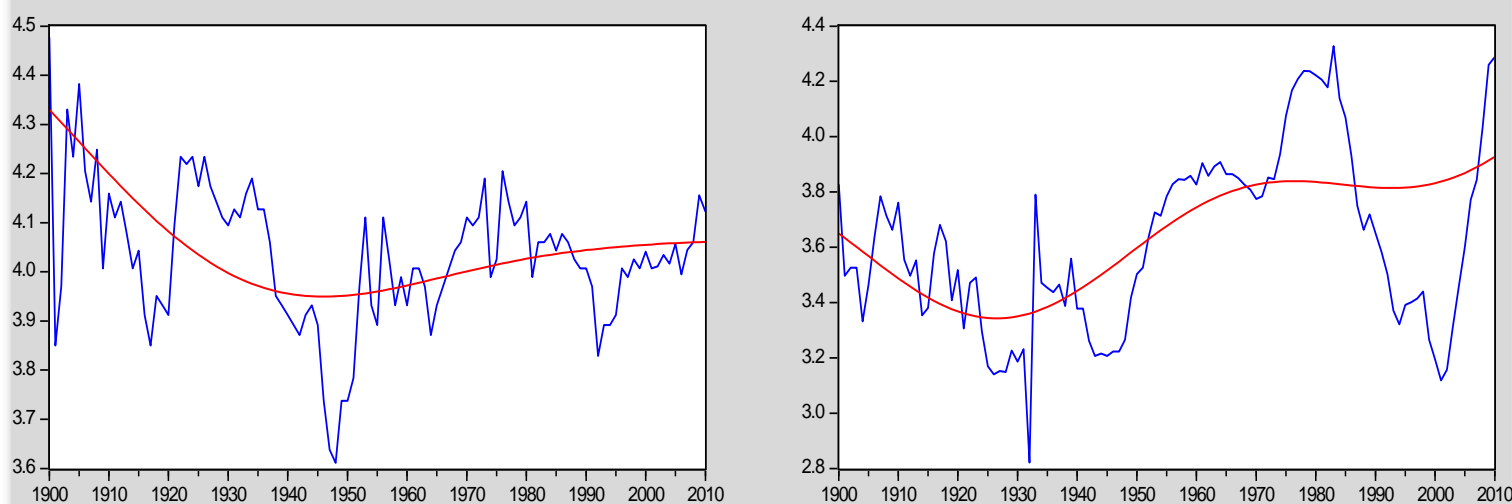

- Iron ore Natural Logs

— Iron ore Long Term Trend w/ Band Pass Filter - BP(>70) Trend 


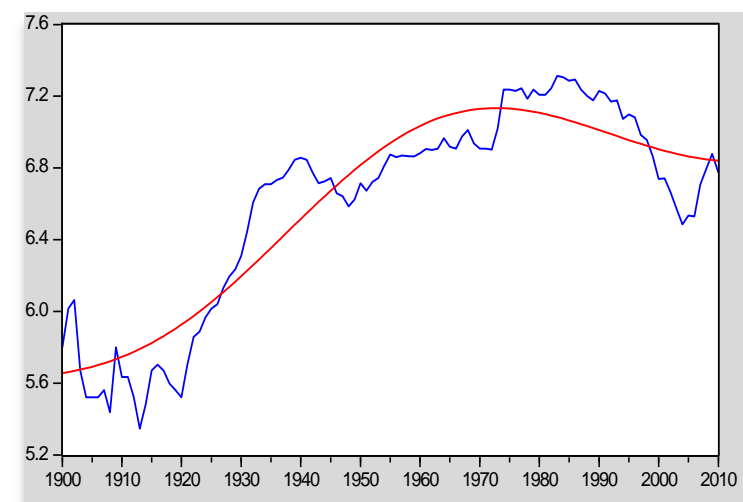

- Iron oxide pigments Natural Logs

— Iron oxide pigments Long Term Trend w/ Band Pass Filter - BP $(>70)$ Trend

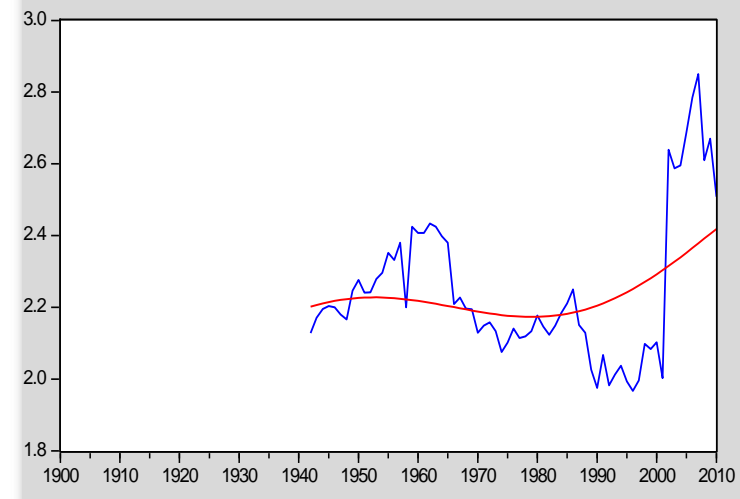

- Iron and steel slag Natural Logs

_ Iron and steel slag Long Term Trend w/ Band Pass Filter - BP $(>70)$ Trend

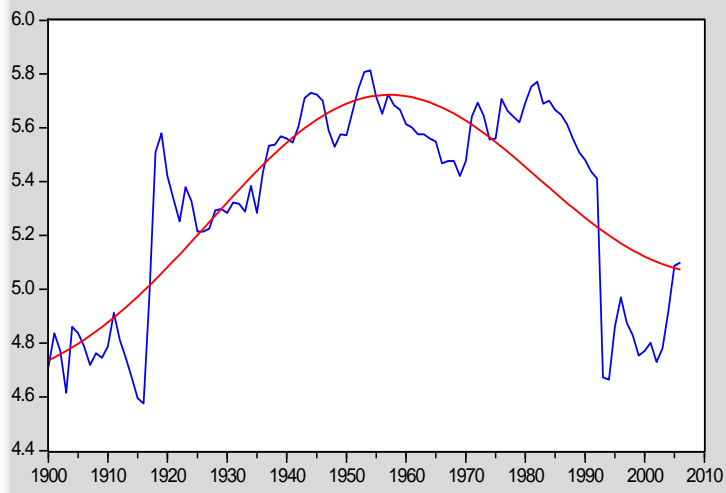

- Fluorspar Natural Logs

_ Fluorspar Long Term Trend w/ Band Pass Filter - BP(>70) Trend

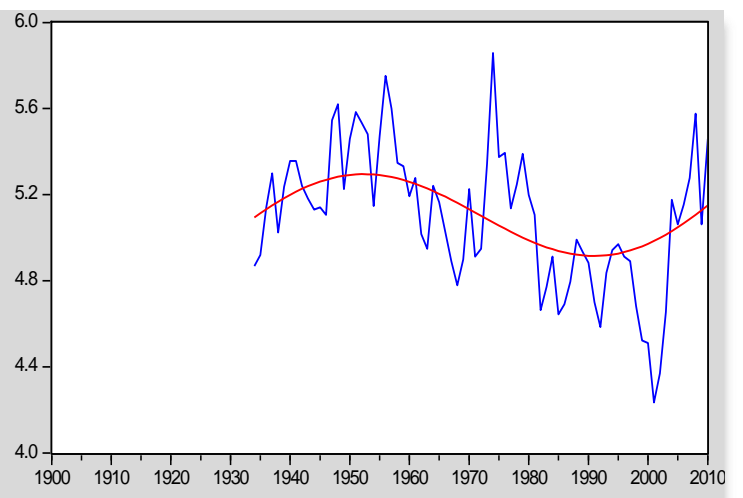

- Iron and steel scrap Natural Logs

_ Iron and steel scrap Long Term Trend w/Band Pass Filter - BP( $>70)$ Trend

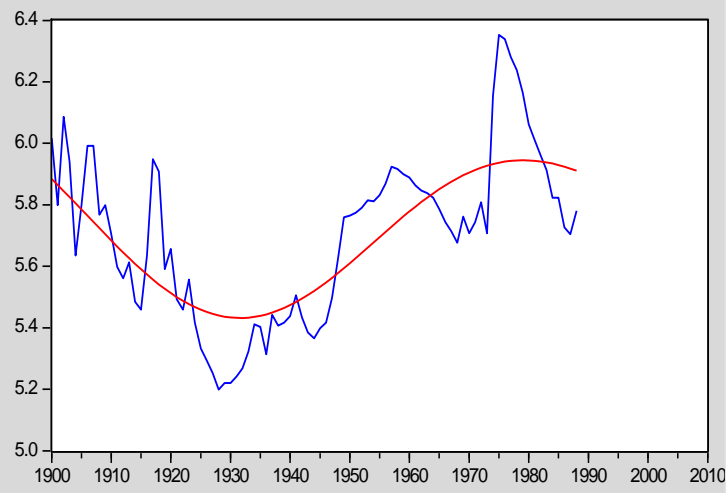

_ Iron and steel Natural Logs

_ Iron and steel Long Term Trend w/ Band Pass Filter - BP(>70) Trend

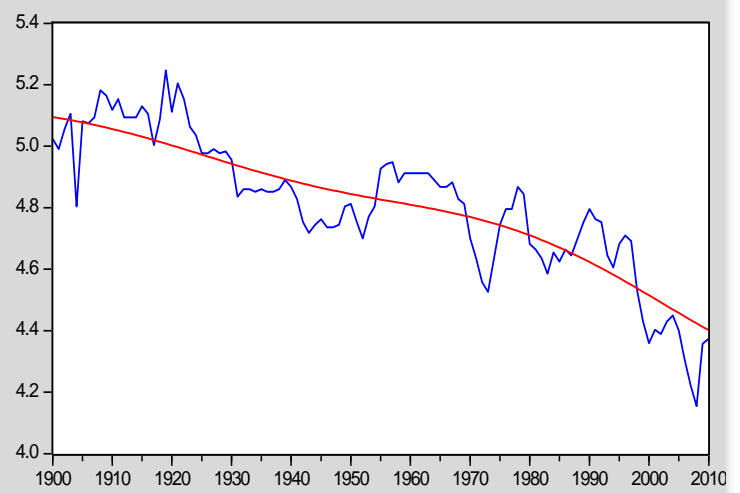

- Clay- Fullers Earth Natural Logs

_ Clay- Fullers Earth Long Term Trend w/ Band Pass Filter - BP(>70) Trend 

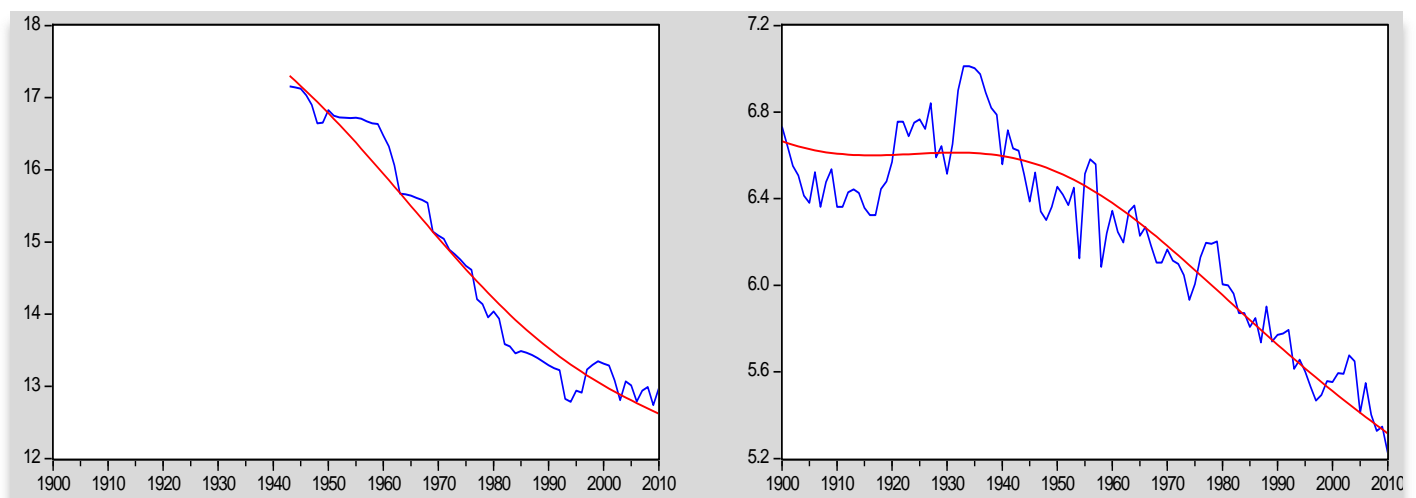

- Gallium Natural Logs

— Gallium Long Term Trend w/Band Pass Filter - BP(>70) Trend

- Garnet (industrial) Natural Logs

— Garnet (industrial) Long Term Trend w/ Band Pass Filter - BP(>70) Trend
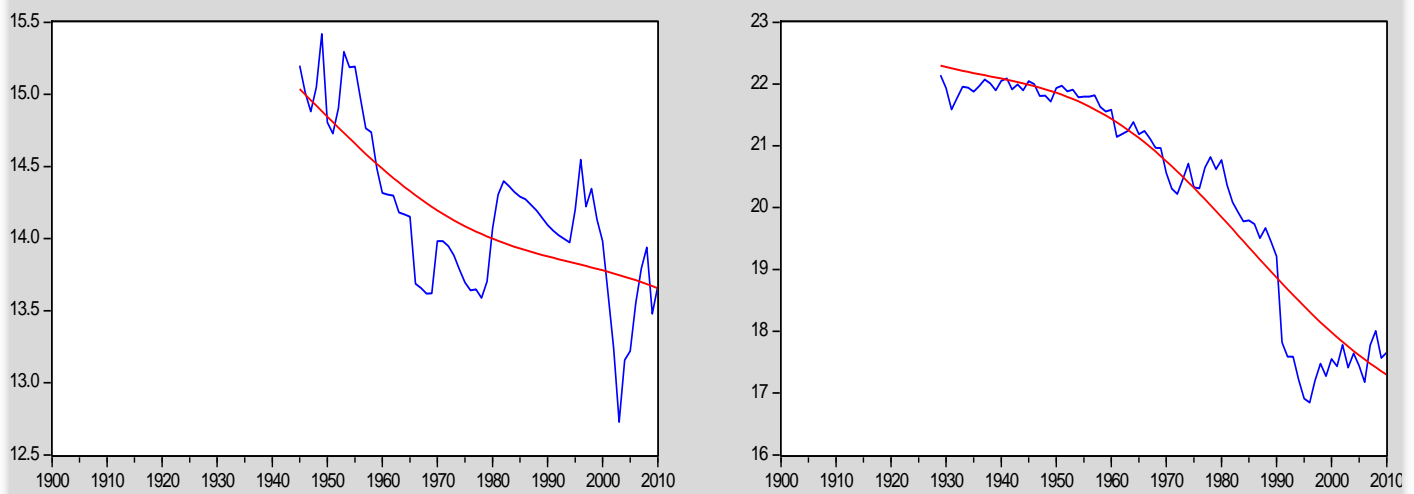

- Germanium Natural Logs

_ Germanium Long Term Trend w/Band Pass Filter - BP(>70) Trend

- Gemstones Natural Logs

— Gemstones Long Term Trend w/ Band Pass Filter - BP(>70) Trend
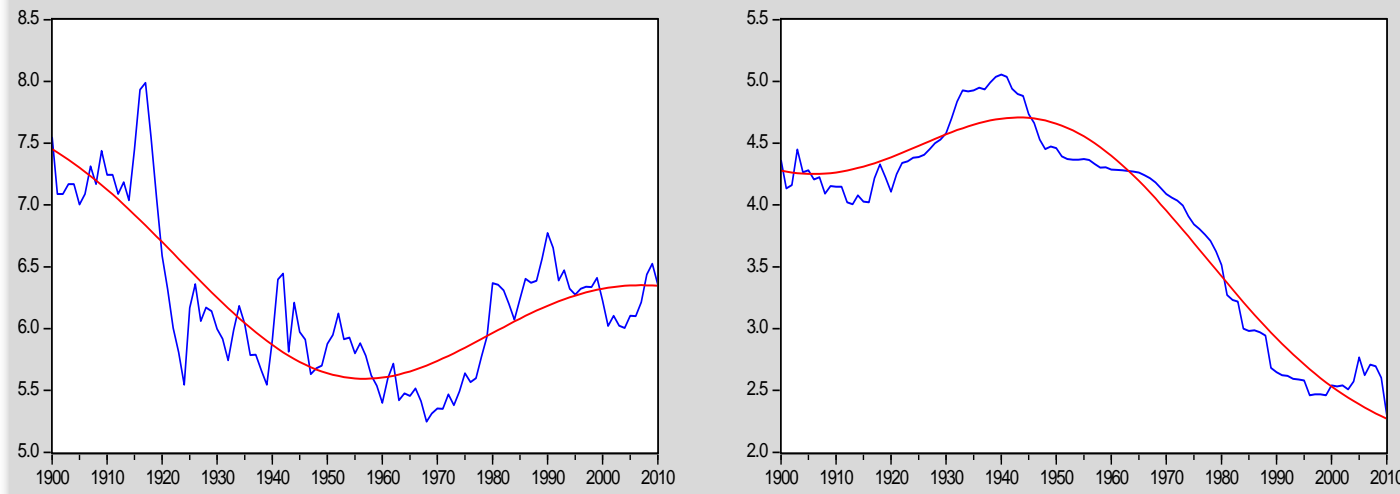

- Graphite (natural) Natural Log 

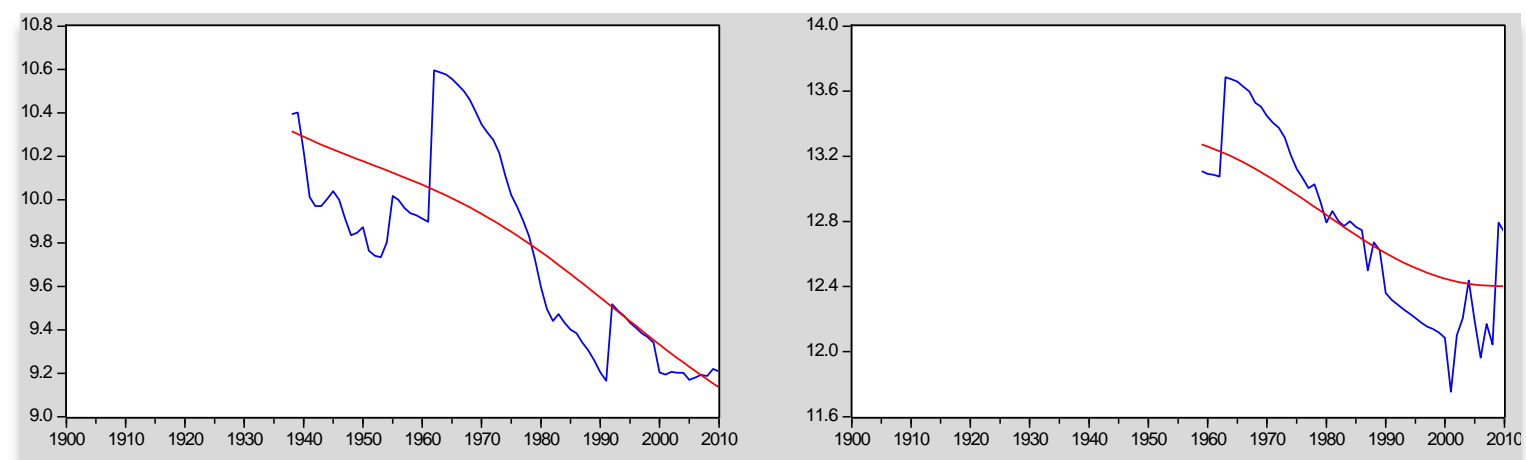

- Helium Natural Logs

Helium Long Term Trend w/ Band Pass Filter - BP( $>70)$ Trend

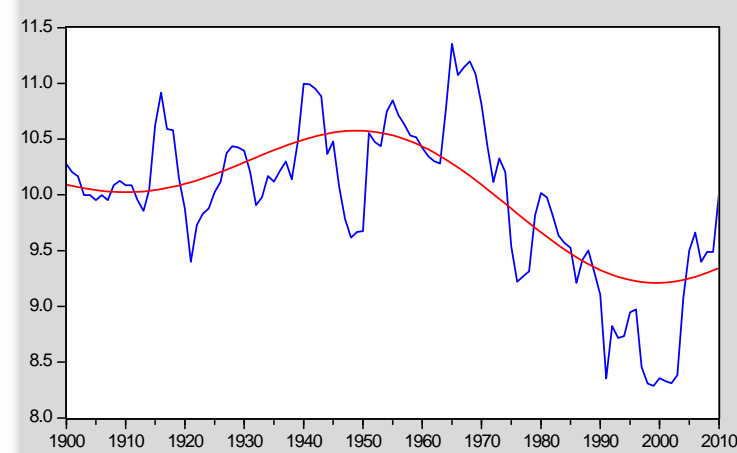

- Hafnium Natural Logs - Hafnium Long Term Trend w/ Band Pass Filter - BP(>70) Trend

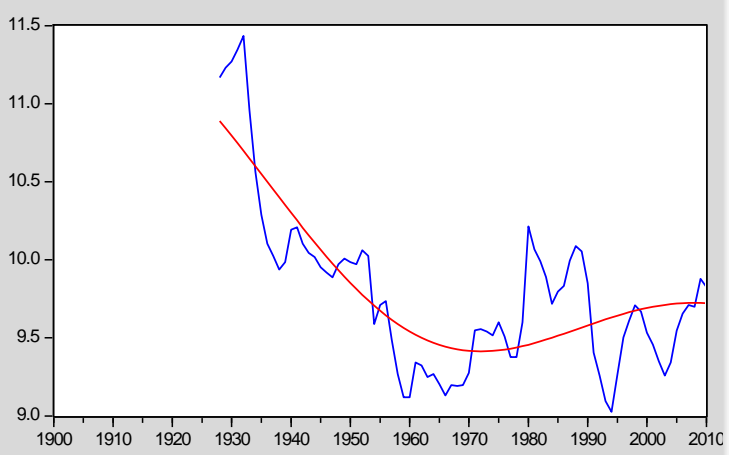

- Mercury Natural Logs

— Mercury Long Term Trend w/ Band Pass Filter - BP(>70) Trend

— lodine Natural Logs

— lodine Long Term Trend w/ Band Pass Filter - BP(>70) Trend
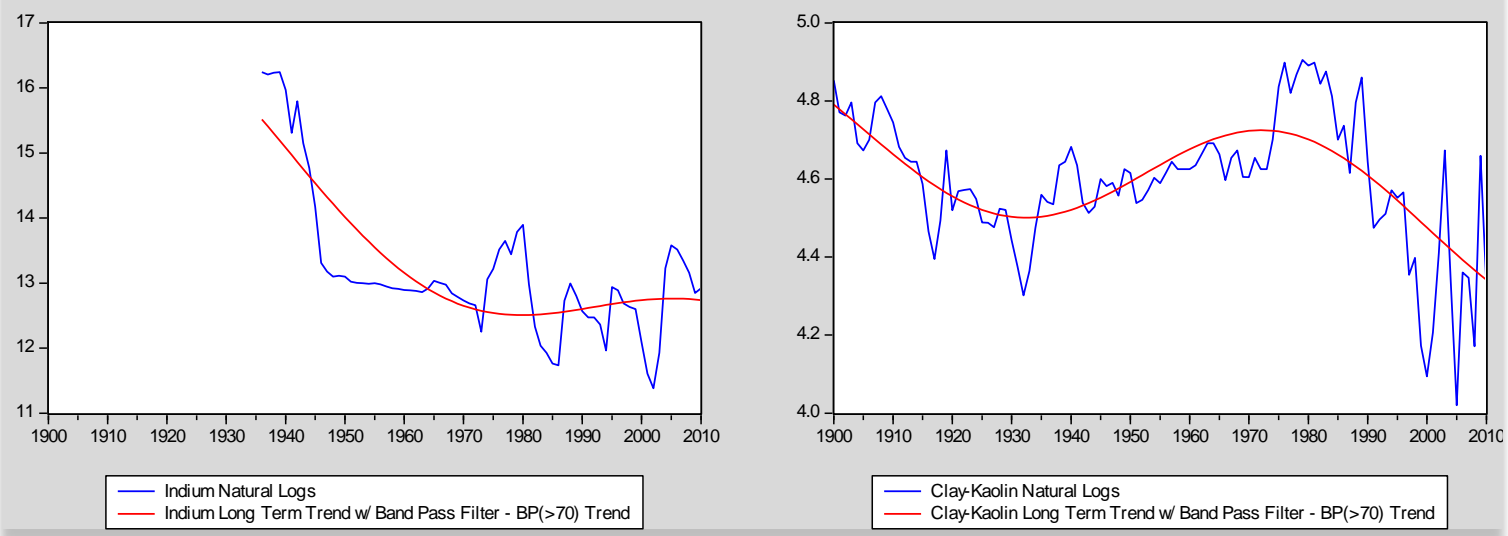

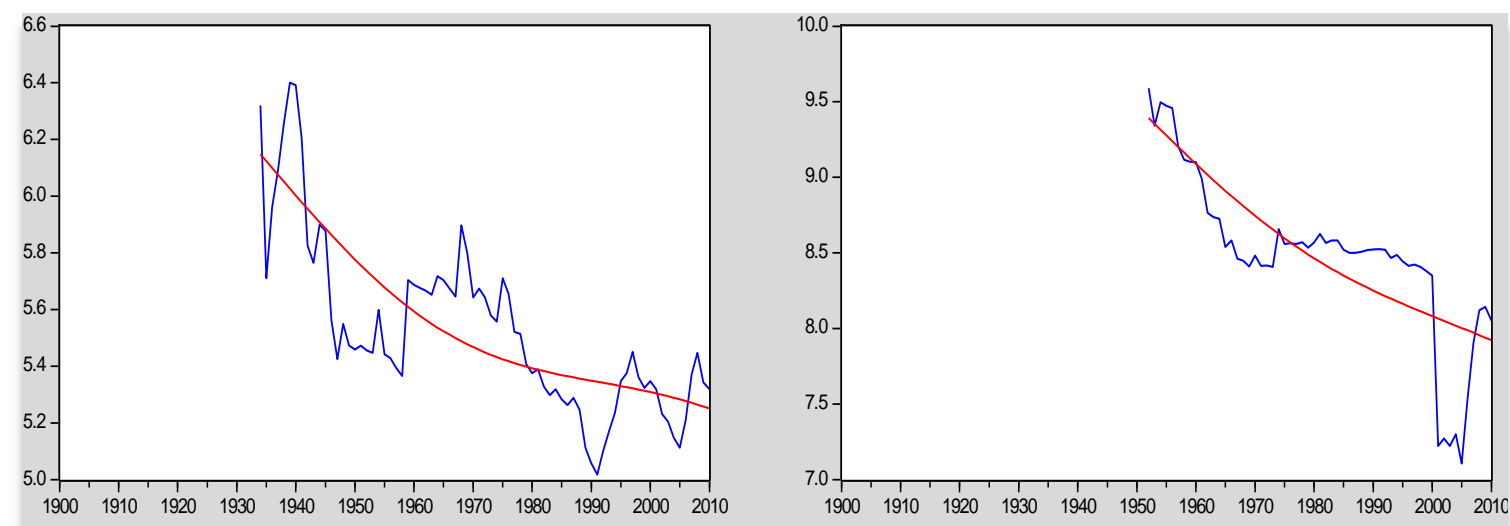

- Kyanite Natural Logs

— Kyanite Long Term Trend w/ Band Pass Filter - BP $(>70)$ Trend

- Lithium Natural Logs

— Lithium Long Term Trend w/ Band Pass Filter - BP(>70) Trend
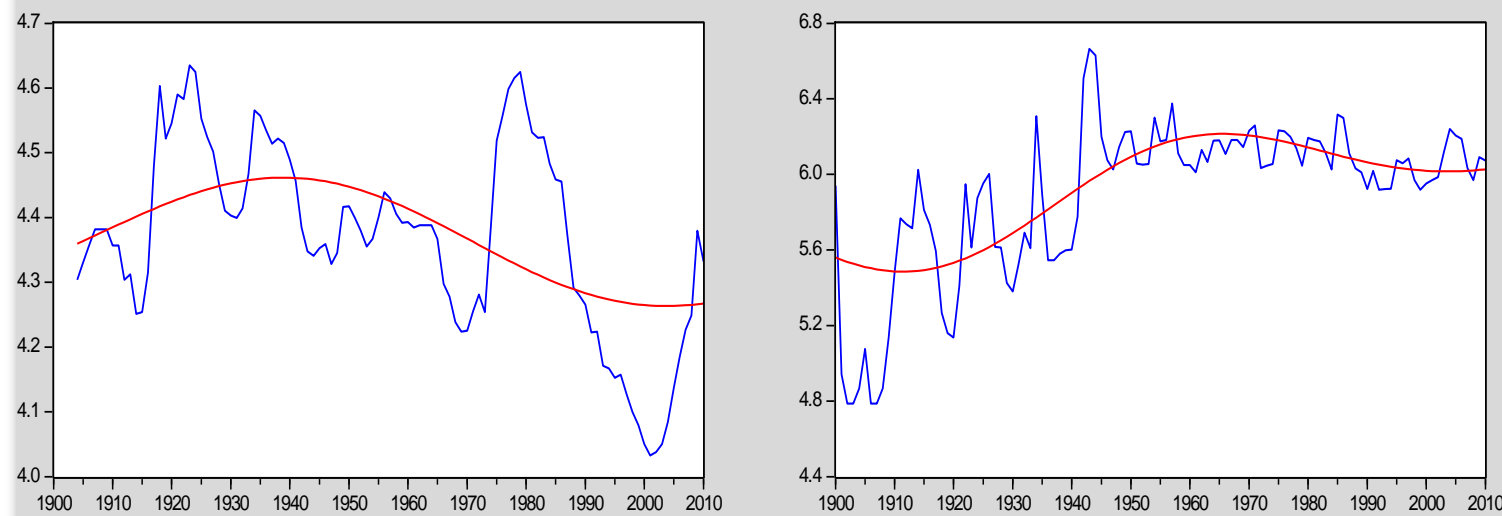

- Lime Natural Logs

— Lime Long Term Trend w/ Band Pass Filter - BP(>70) Trend

- Magnesium compounds Natural Logs

— Magnesium compounds Long Term Trend w/ Band Pass Filter - BP(>70) Trend
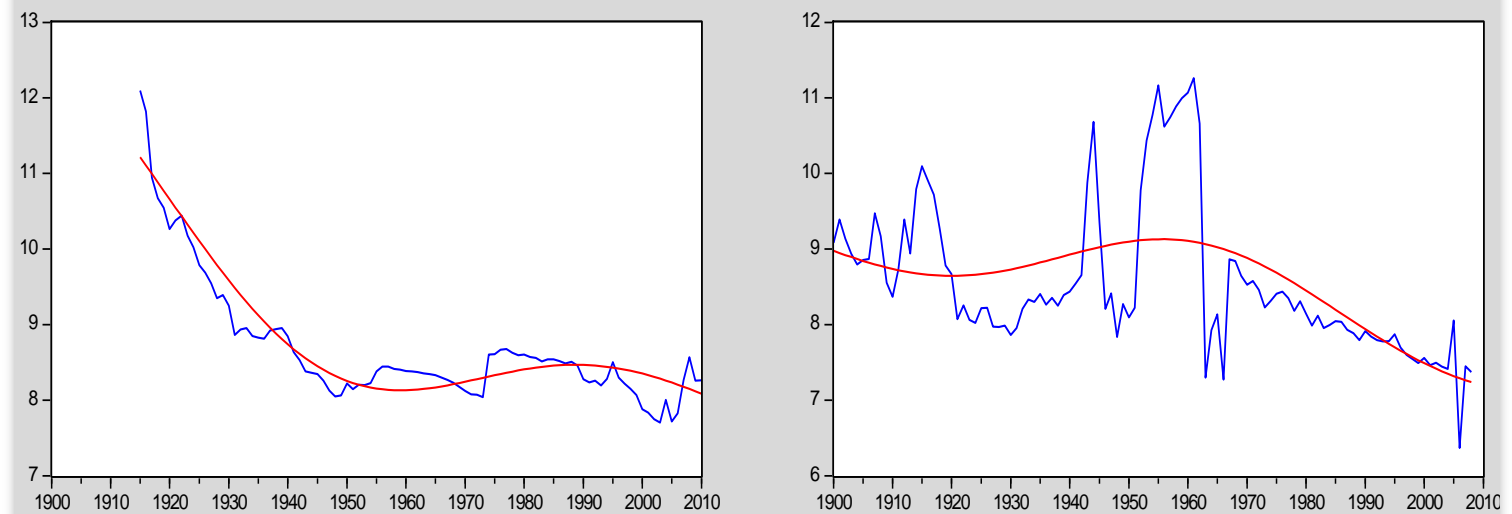

- Magnesium metal Natural Logs

Magnesium metal Long Term Trend w/ Band Pass Filter - BP(>70) Trend 

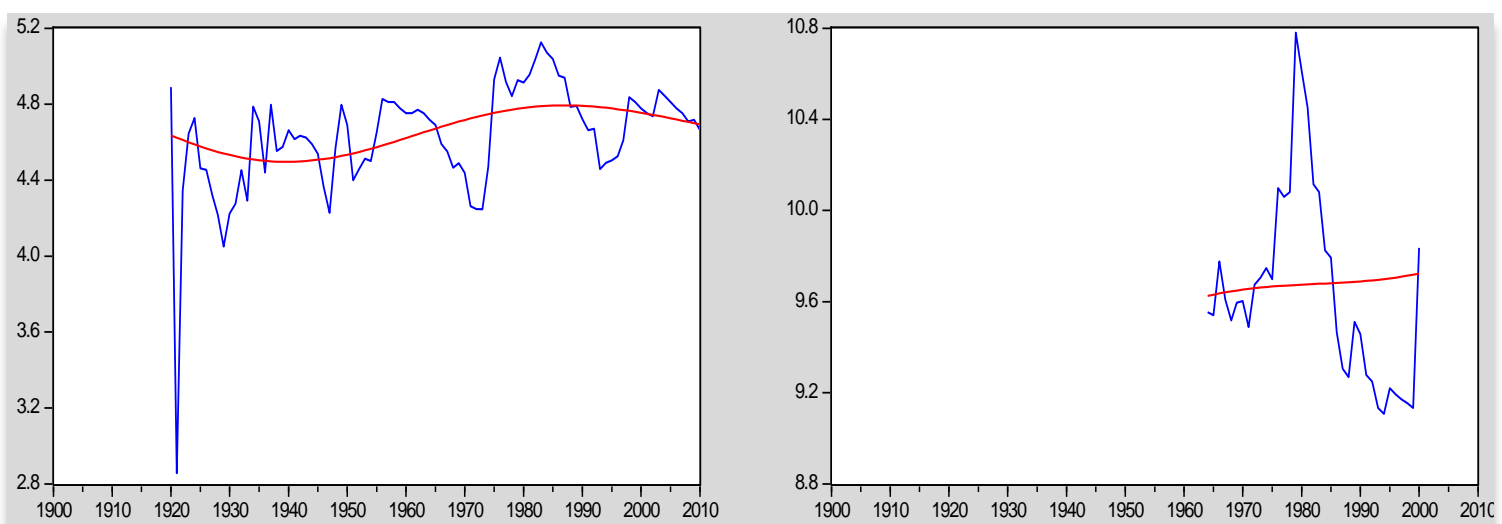

— Sodium sulfate Natural Logs

— Sodium sulfate Long Term Trend w/ Band Pass Filter - BP(>70) Trend
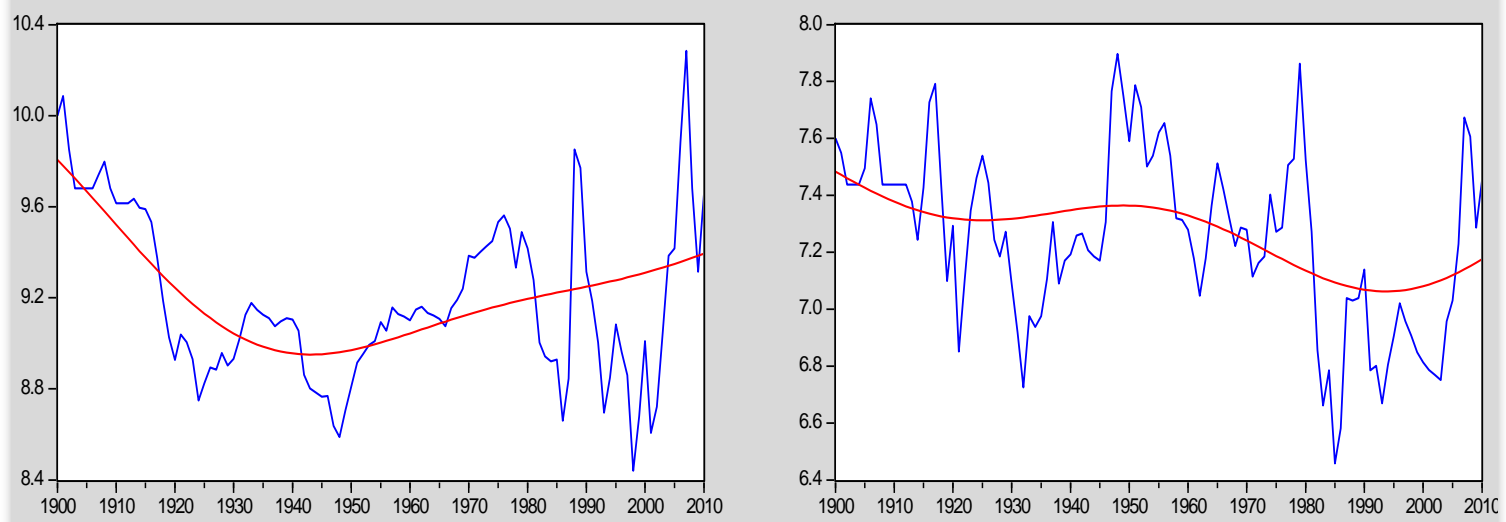

- Nickel Natural Logs

- Nickel Long Term Trend w/ Band Pass Filter - BP $(>70)$ Trend

- Lead Natural Logs

— Lead Long Term Trend w/ Band Pass Filter - BP(>70) Trend
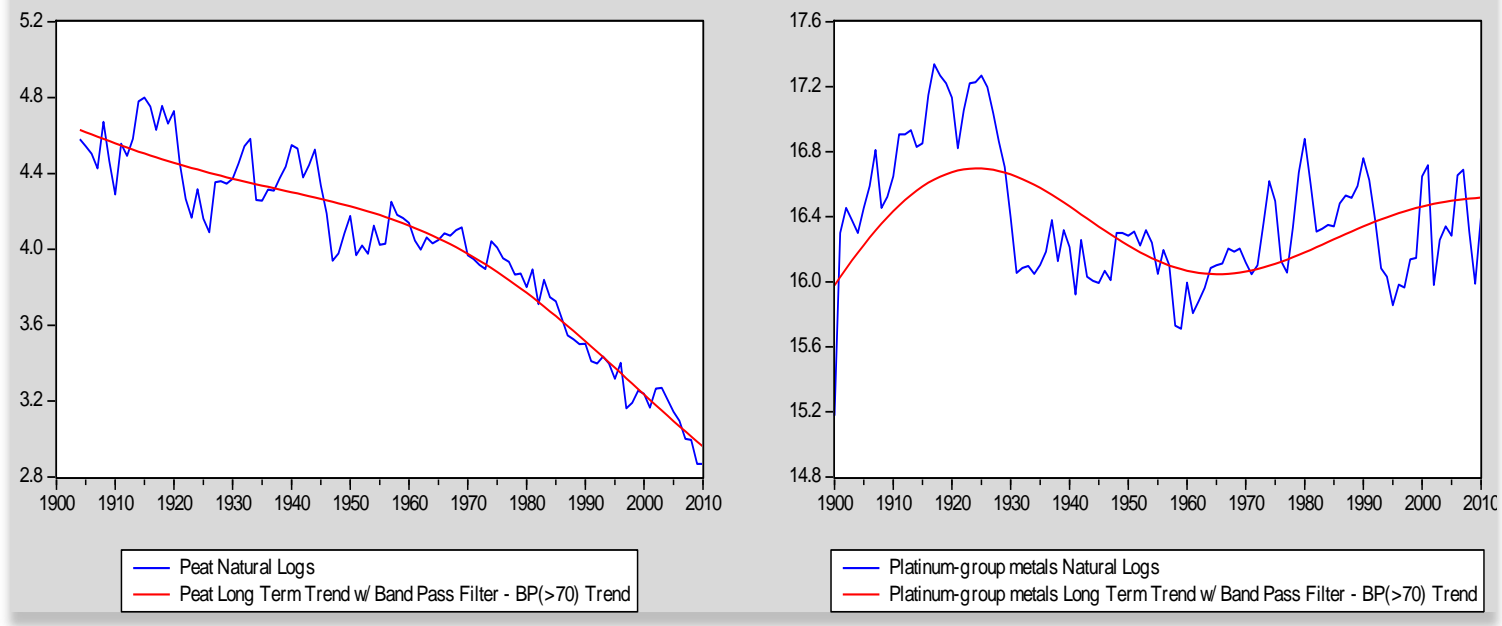

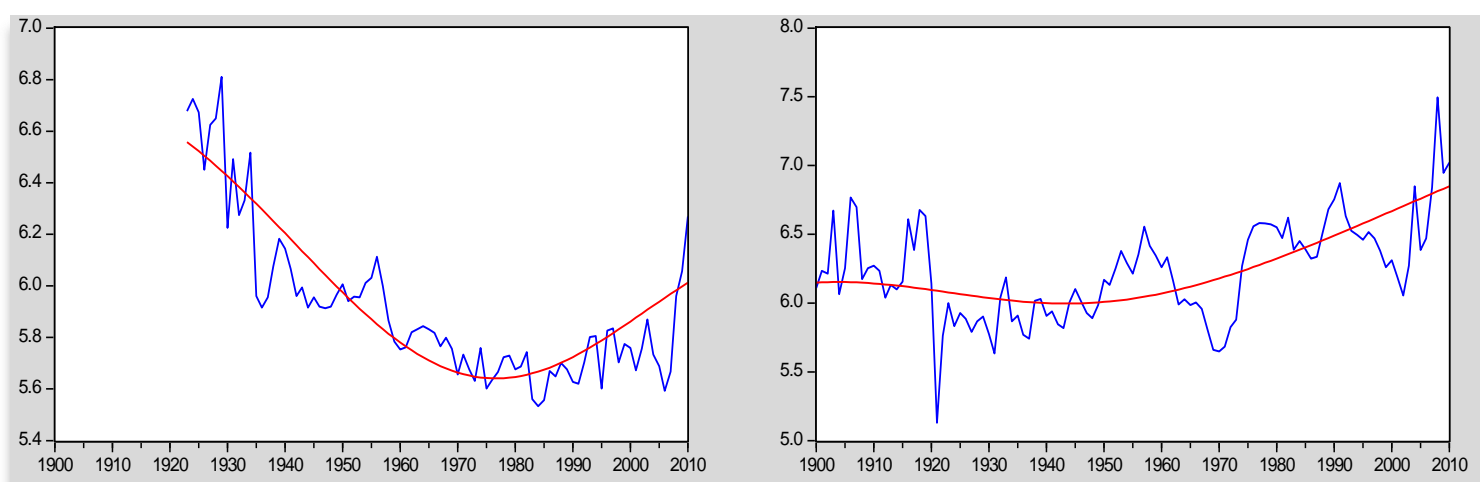

- Mica (scrap and flake) Natural Logs

Mica (scrap and flake) Long Term Trend w/ Band Pass Filter - BP(>70) Trend

- Manganese Natural Log

- Manganese Long Term Trend w/ Band Pass Filter - BP $(>70)$ Trend
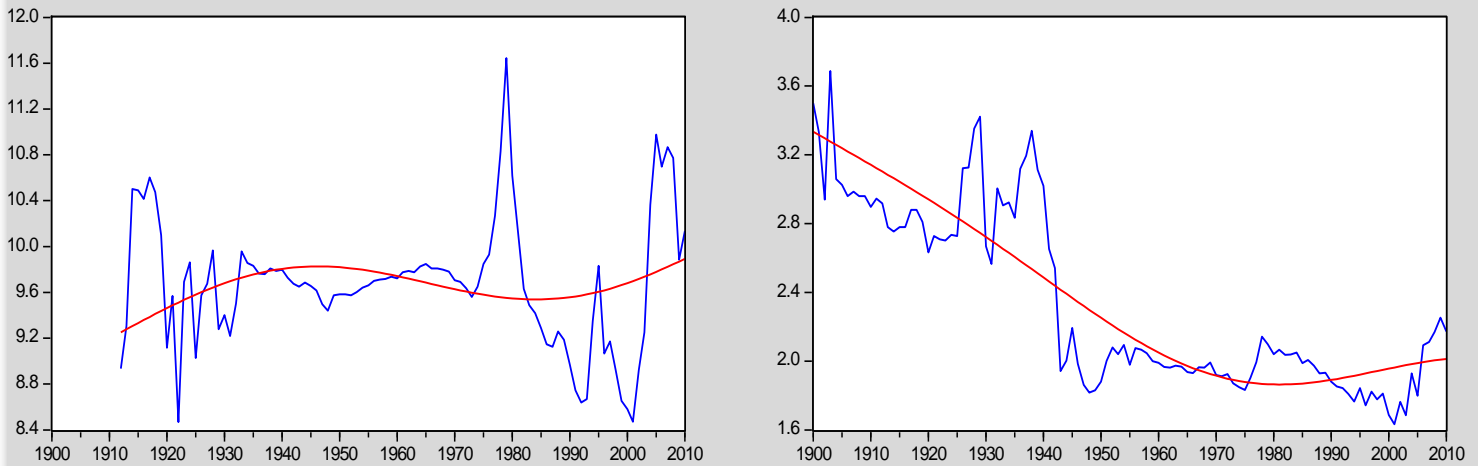

- Molybdenum Natural Logs

— Molybdenum Long Term Trend w/ Band Pass Filter - BP(>70) Trend

- Clay-Miscellaneous clay and shale Natural Logs

_ Clay-Miscellaneous clay and shale Long Term Trend w/Band Pass Filter - BP $(>70)$ Trend
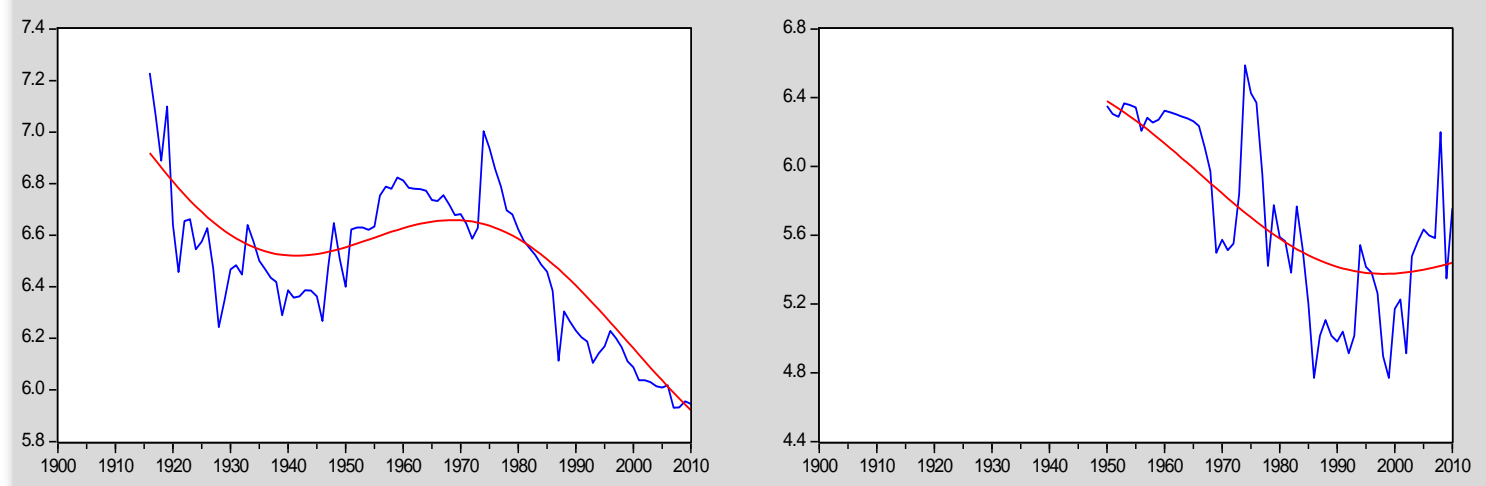

- Metallic Abrasives Natural Log

- Metallic Abrasives Long Term Trend w/ Band Pass Filter - BP(>70) Trend 


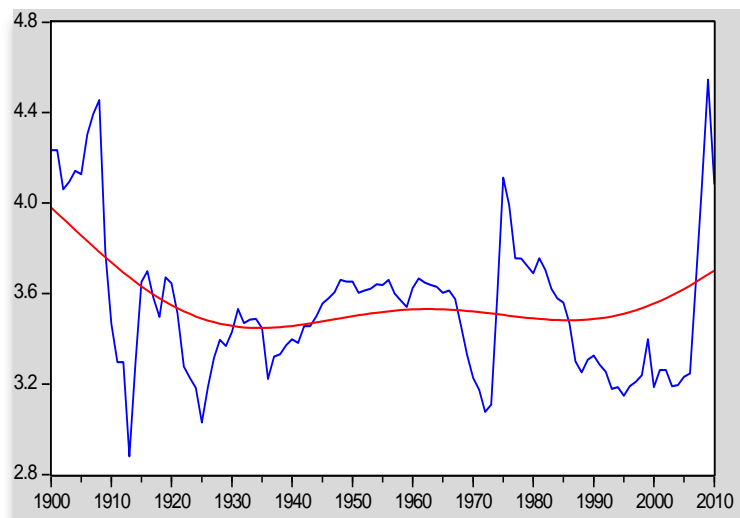

- Phosphate rock Natural Logs

_ Phosphate rock Long Term Trend w/ Band Pass Filter - BP(>70) Trend

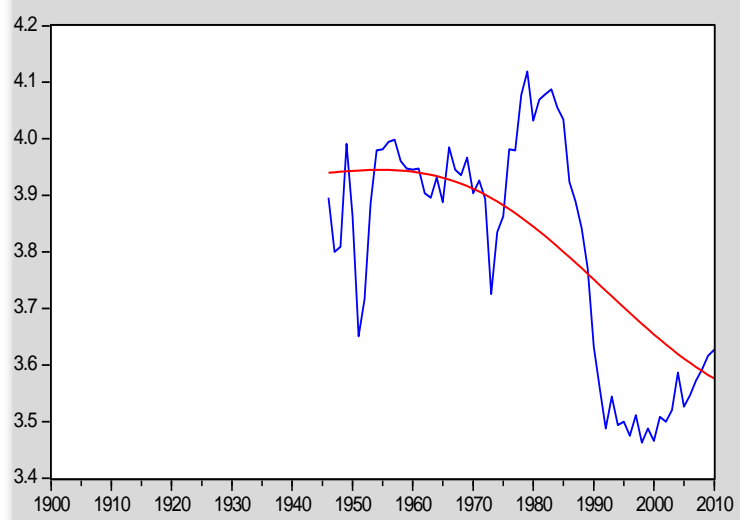

- Perlite Natural Logs

_ Perlite Long Term Trend w/ Band Pass Filter - BP( $>70)$ Trend

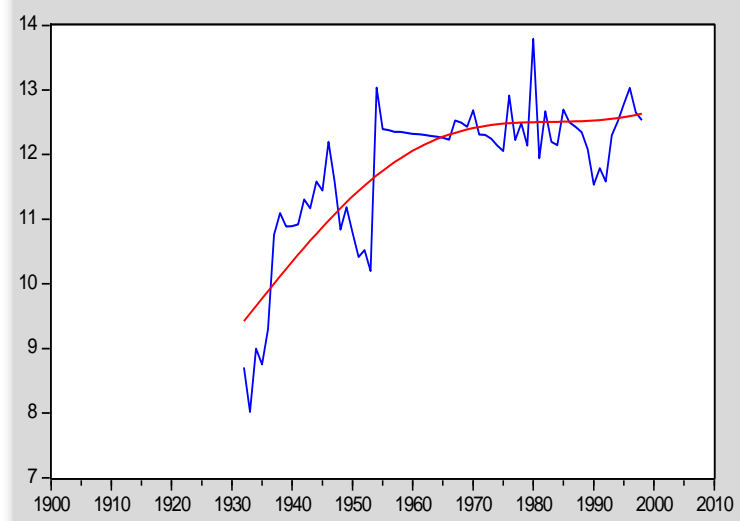

— Quartz crystal (industrial) Natural Logs

— Quartz crystal (industrial) Long Term Trend w/ Band Pass Filter - BP(>70) Trend

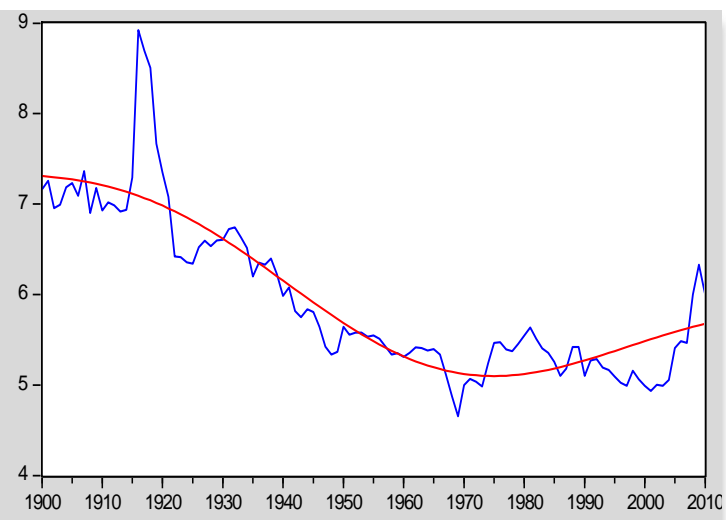

- Potash Natural Logs

_ Potash Long Term Trend w/ Band Pass Filter - BP( $>70)$ Trend

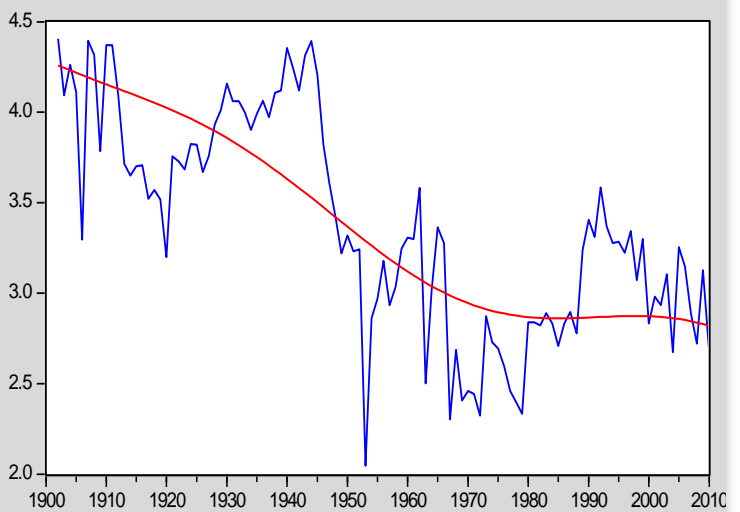

- Pumice and pumicite Natural Logs

- Pumice and pumicite Long Term Trend w/ Band Pass Filter - BP $(>70)$ Trend

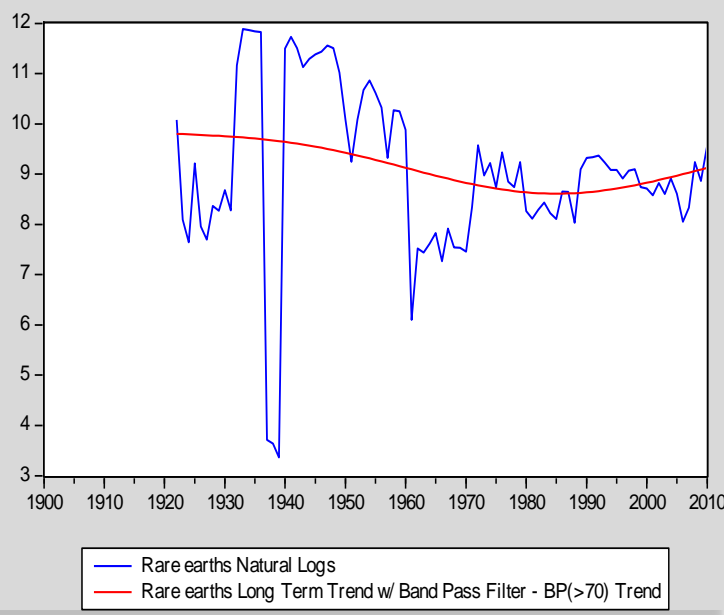



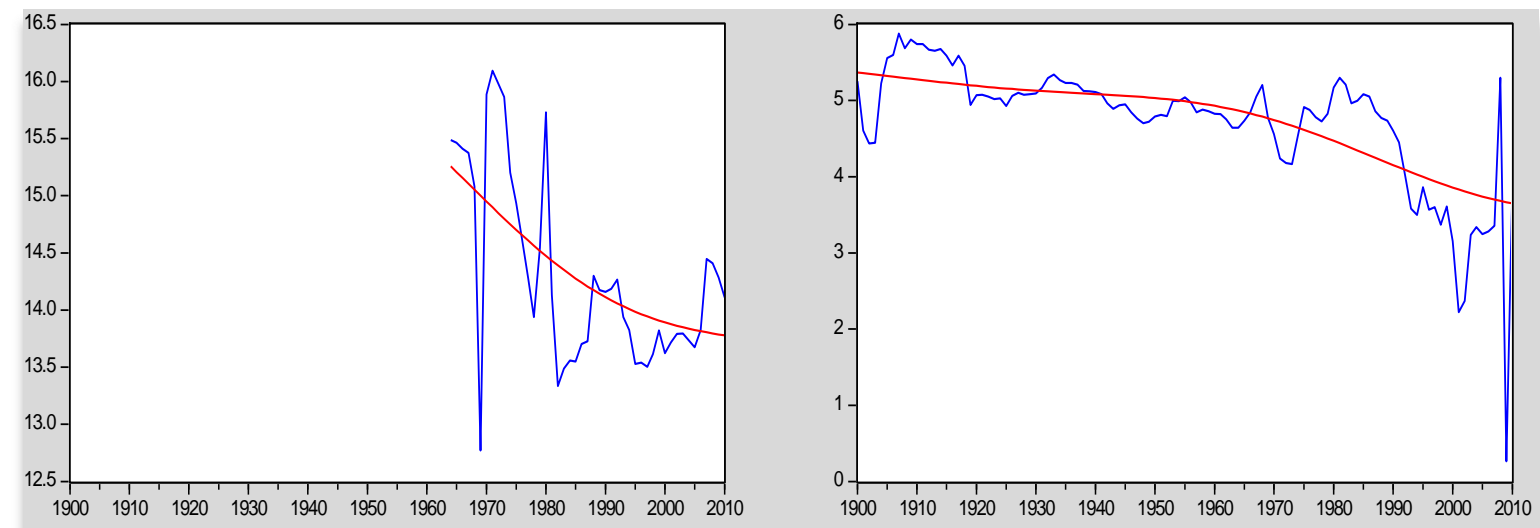

- Rhenium Natural Logs

— Rhenium Long Term Trend w/Band Pass Filter - BP(>70) Trend
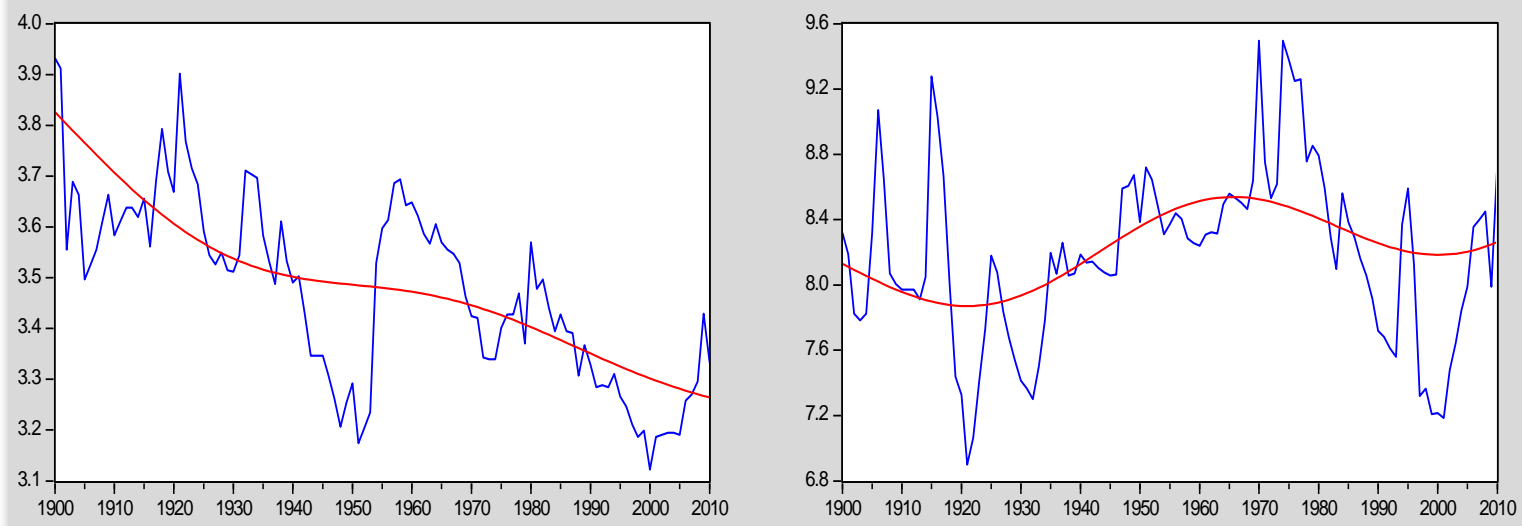

- Salt Natural Logs

_ Salt Long Term Trend w/ Band Pass Filter - BP(>70) Trend

- Antimony Natural Logs

— Antimony Long Term Trend w/ Band Pass Filter - BP(>70) Trend
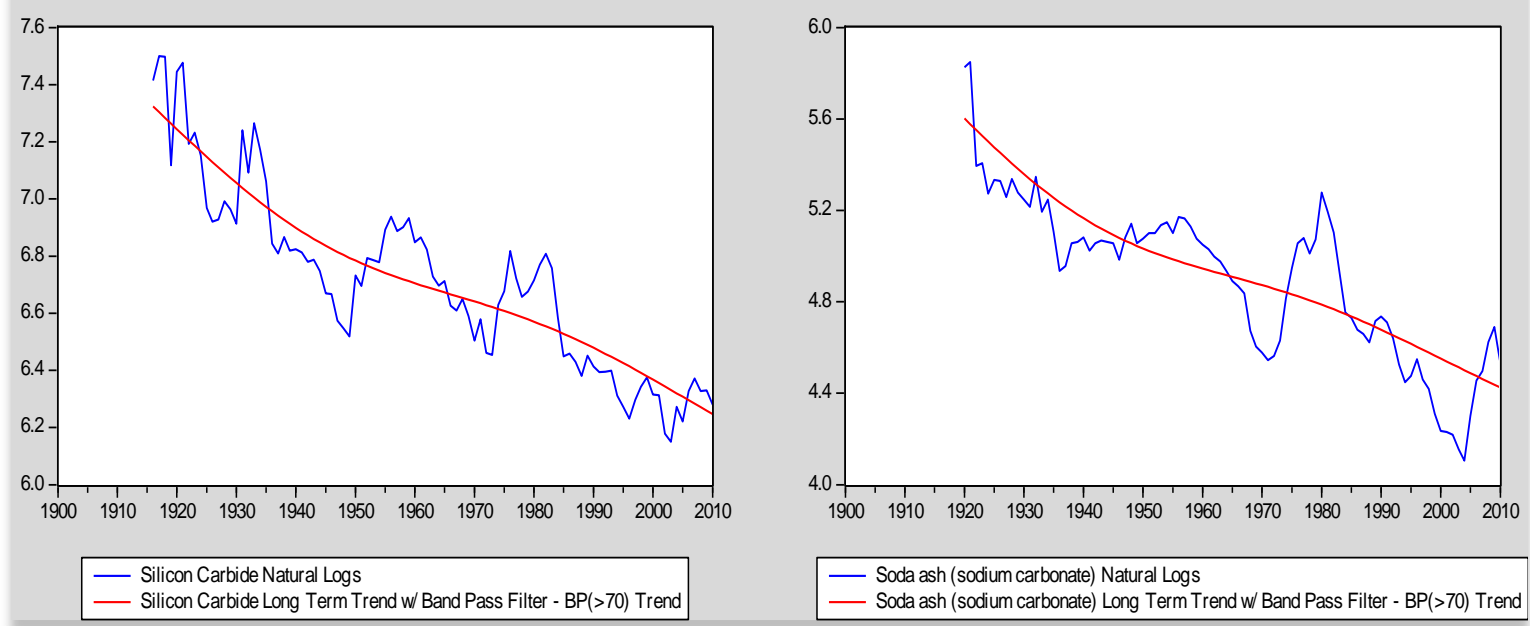

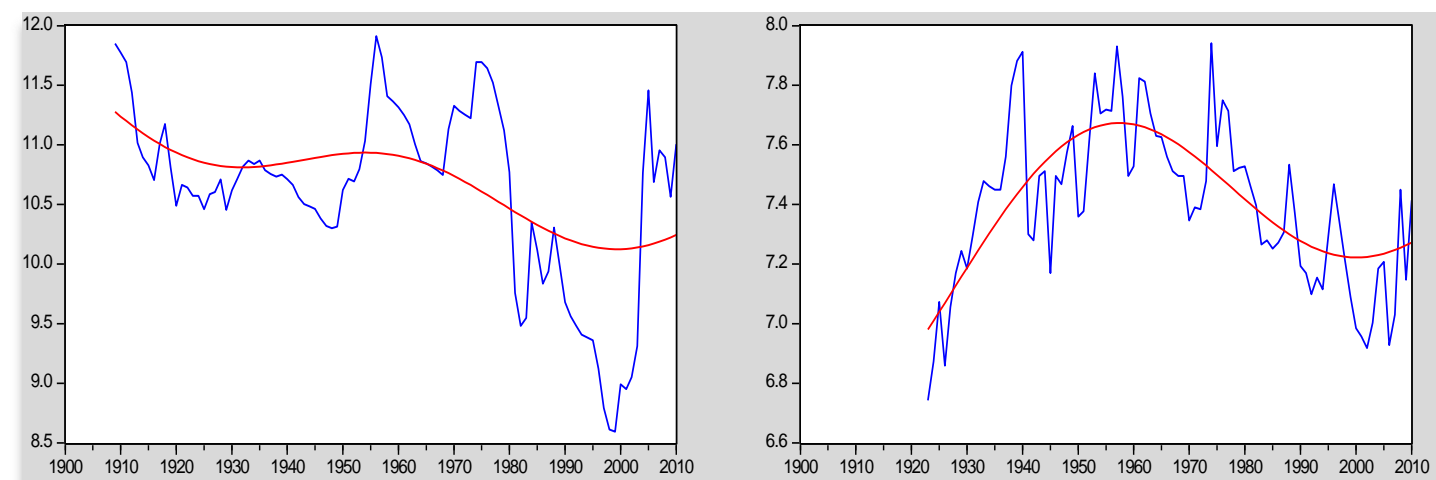

- Selenium Natural Logs

Selenium Long Term Trend w/ Band Pass Filter - BP(>70) Trend

- Silicon Natural Logs

_ Silicon Long Term Trend w/ Band Pass Filter - BP(>70) Trend
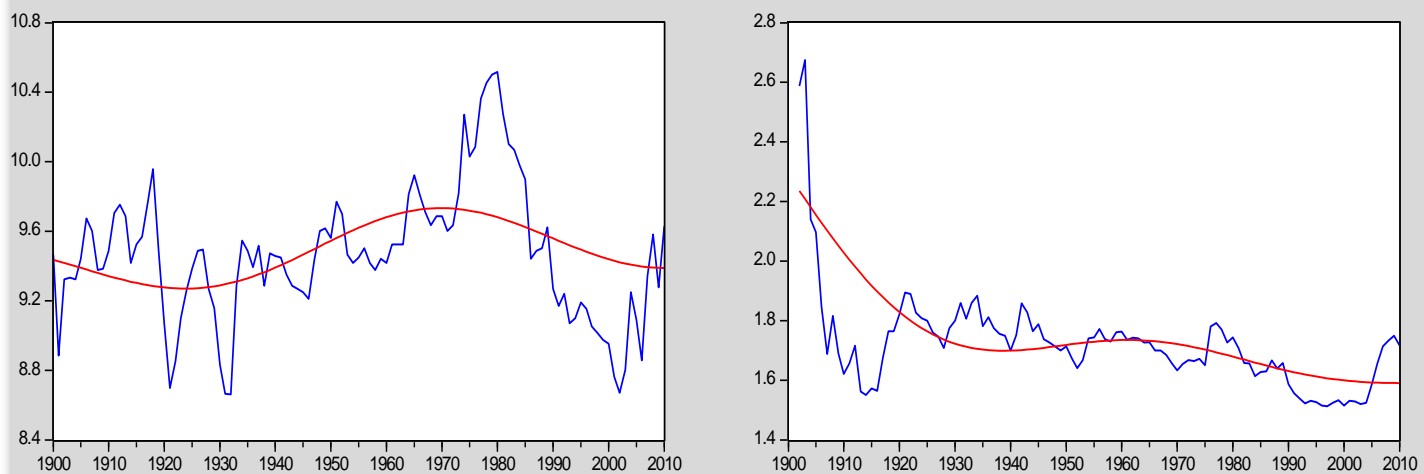

— Tin Natural Logs

— Tin Long Term Trend w/ Band Pass Filter - BP( $>70)$ Trend

- Sand and gravel (construction) Natural Logs
- Sand and gravel (construction) Long Term Trend w/ Band Pass Filter - BP $(>70)$ Trend
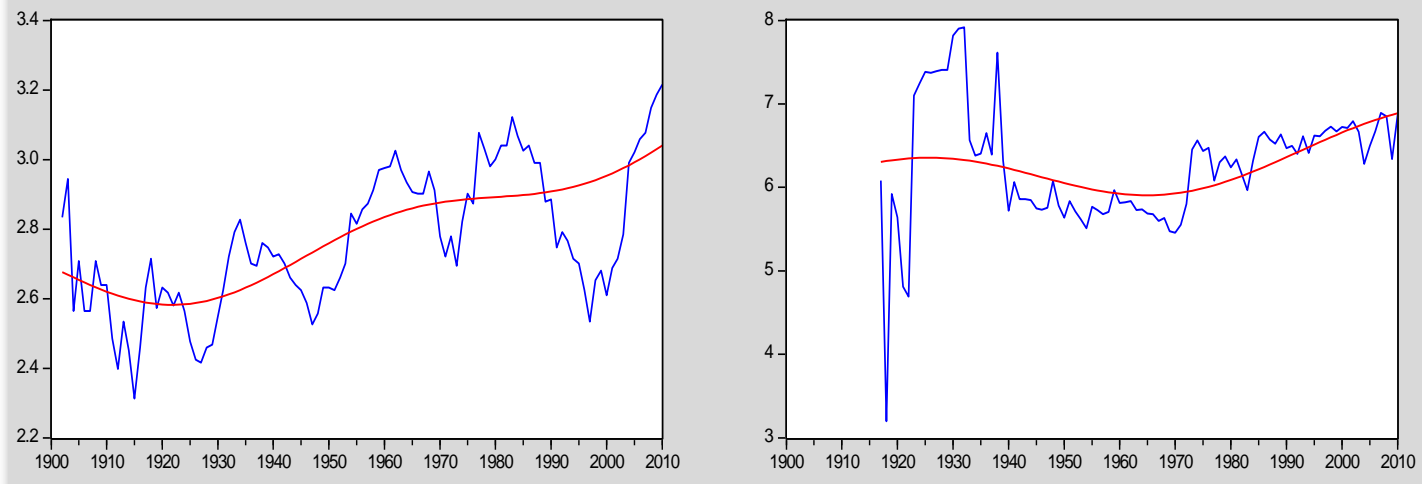

- Sand and gravel (industrial) Natural Log

Sand and gravel (industrial) Long Term Trend w/ Band Pass Filter - BP( $>70)$ Trend

- Strontium Natural Logs

- Strontium Natural Logs
- Strontium Long Term Trend w/ Band Pass Filter - BP $(>70)$ Trend 

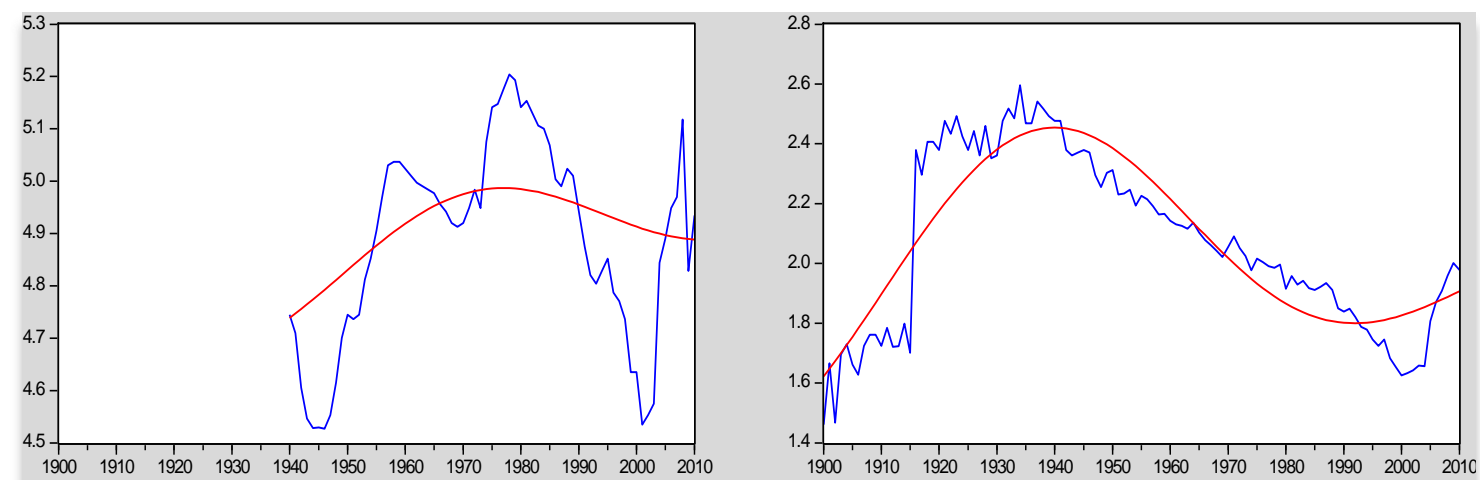

- Steel Natural Logs

- Steel Long Term Trend w/ Band Pass Filter - BP $(>70)$ Trend

- Stone (crushed) Natural Logs

— Stone (crushed) Long Term Trend w/ Band Pass Filter - BP(>70) Trend
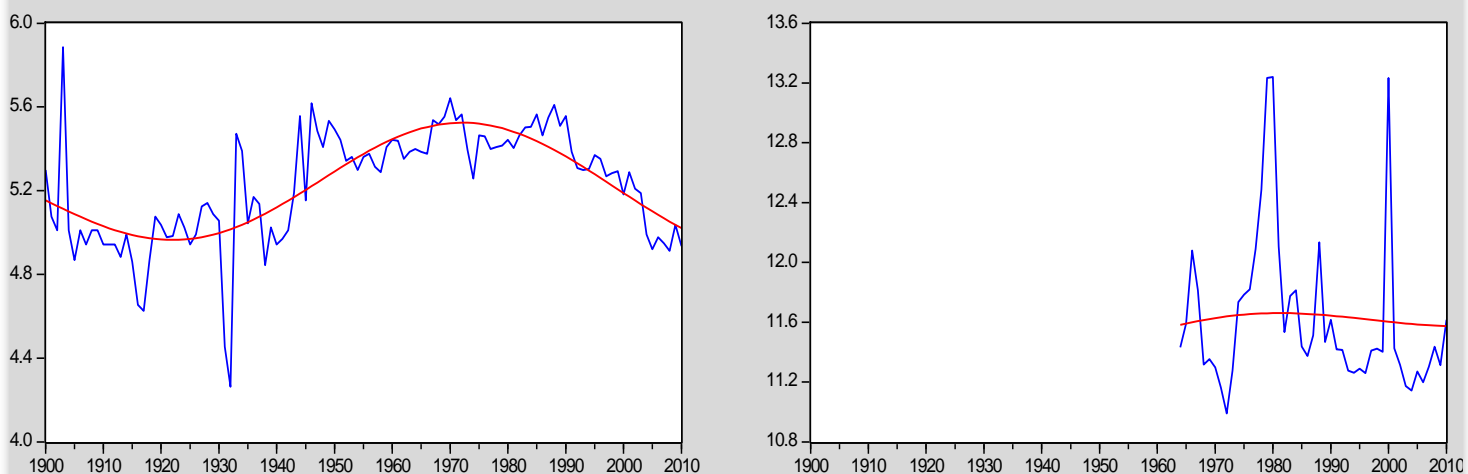

- Stone (dimension) Natural Logs

_ Stone (dimension) Long Term Trend w/ Band Pass Filter - BP( $>70)$ Trend
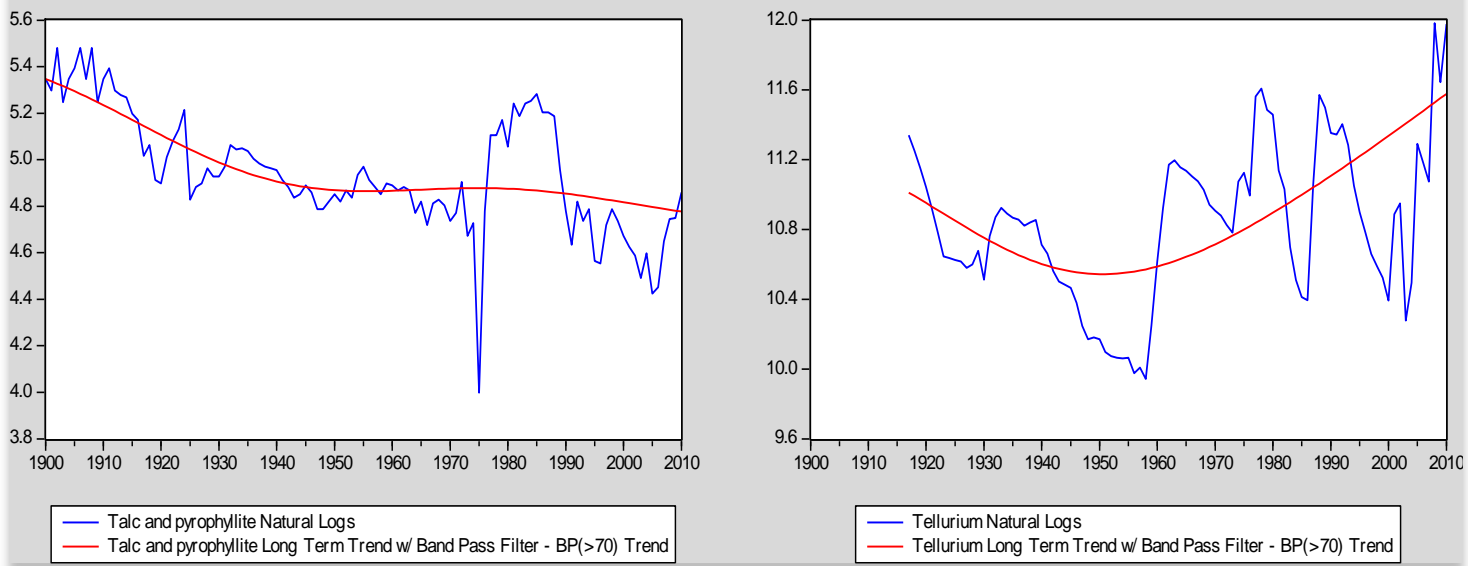

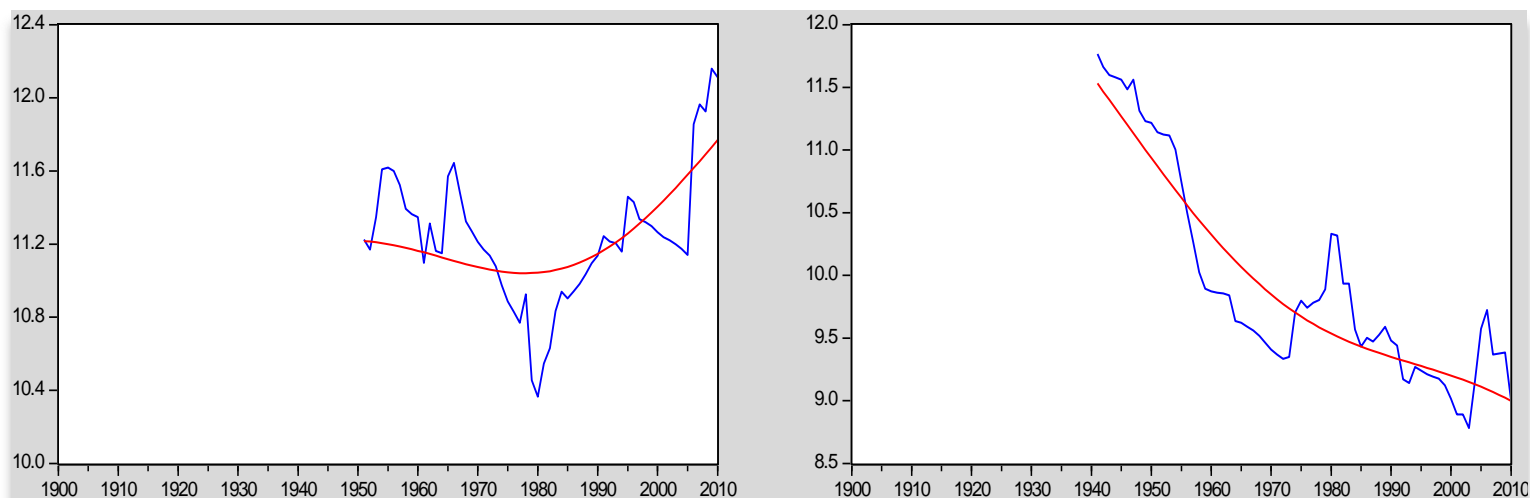

- Thorium Natural Logs

_ Thorium Long Term Trend w/ Band Pass Filter - BP $(>70)$ Trend
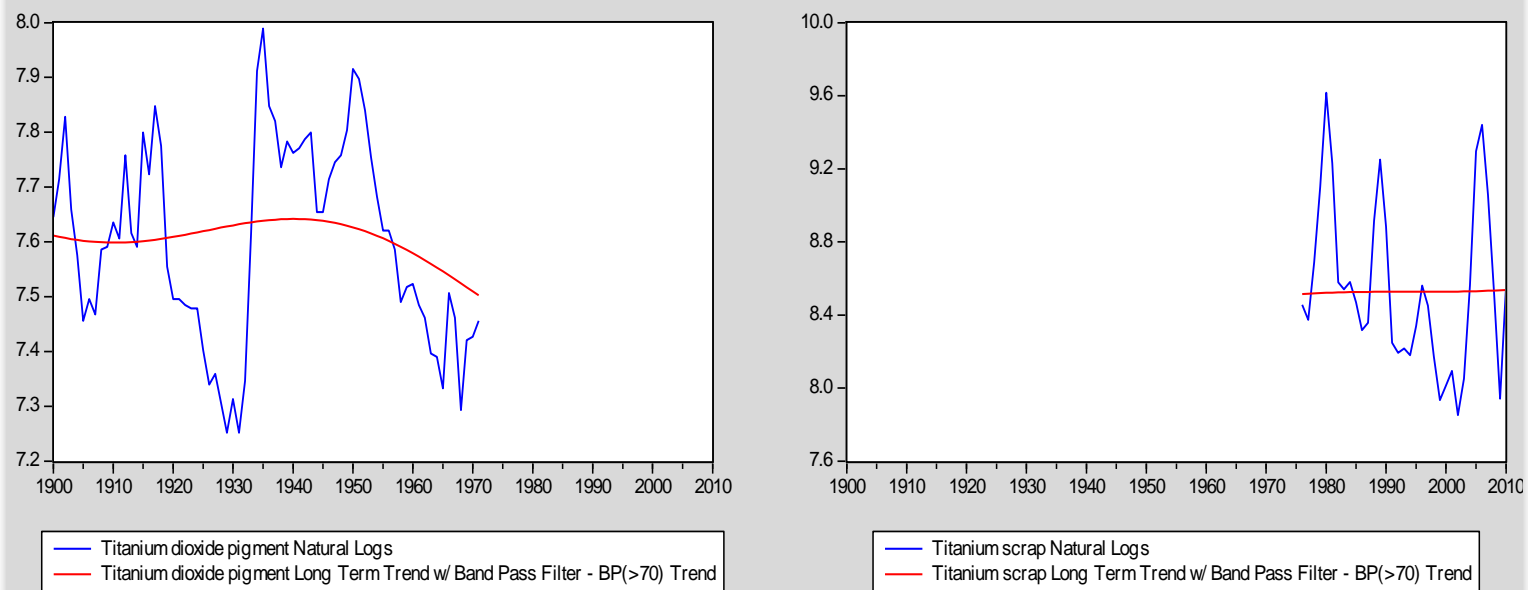

$\begin{array}{llllllllllll}1900 & 1910 & 1920 & 1930 & 1940 & 1950 & 1960 & 1970 & 1980 & 1990 & 2000 & 2010\end{array}$

_ Titanium scrap Natural Logs

— Titanium scrap Long Term Trend w/ Band Pass Filter - BP $(>70)$ Trend
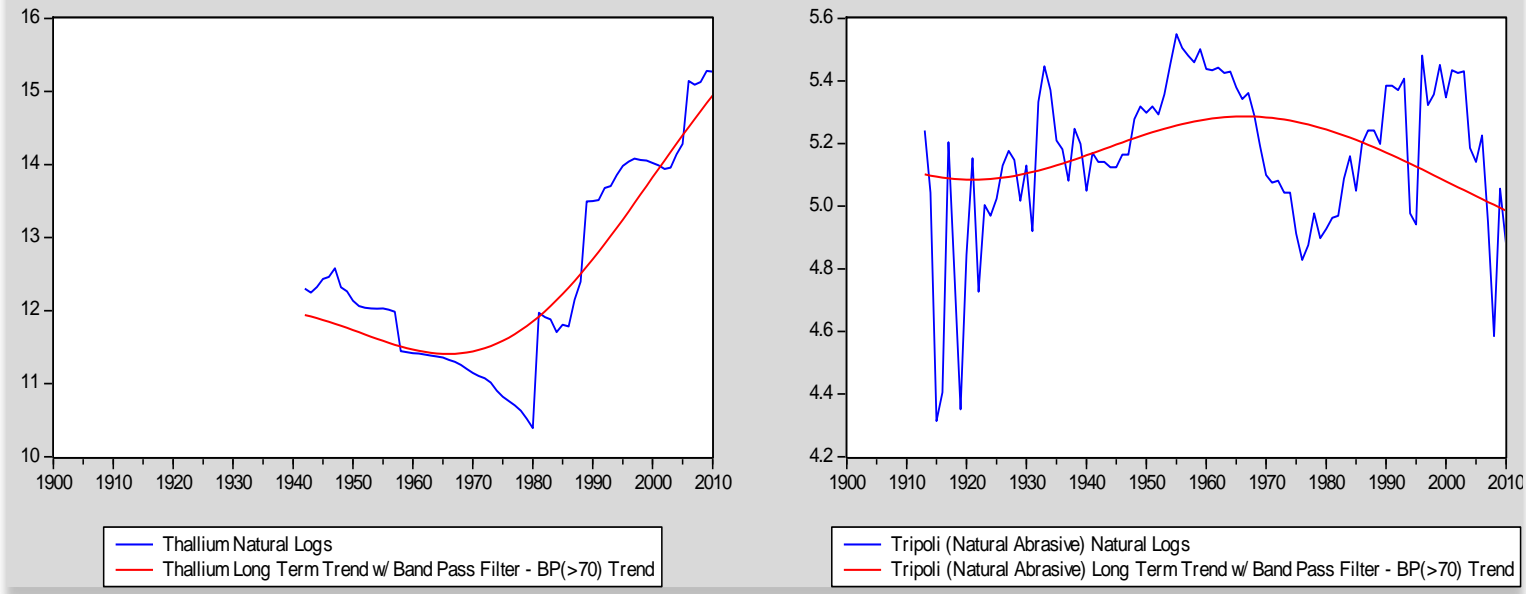

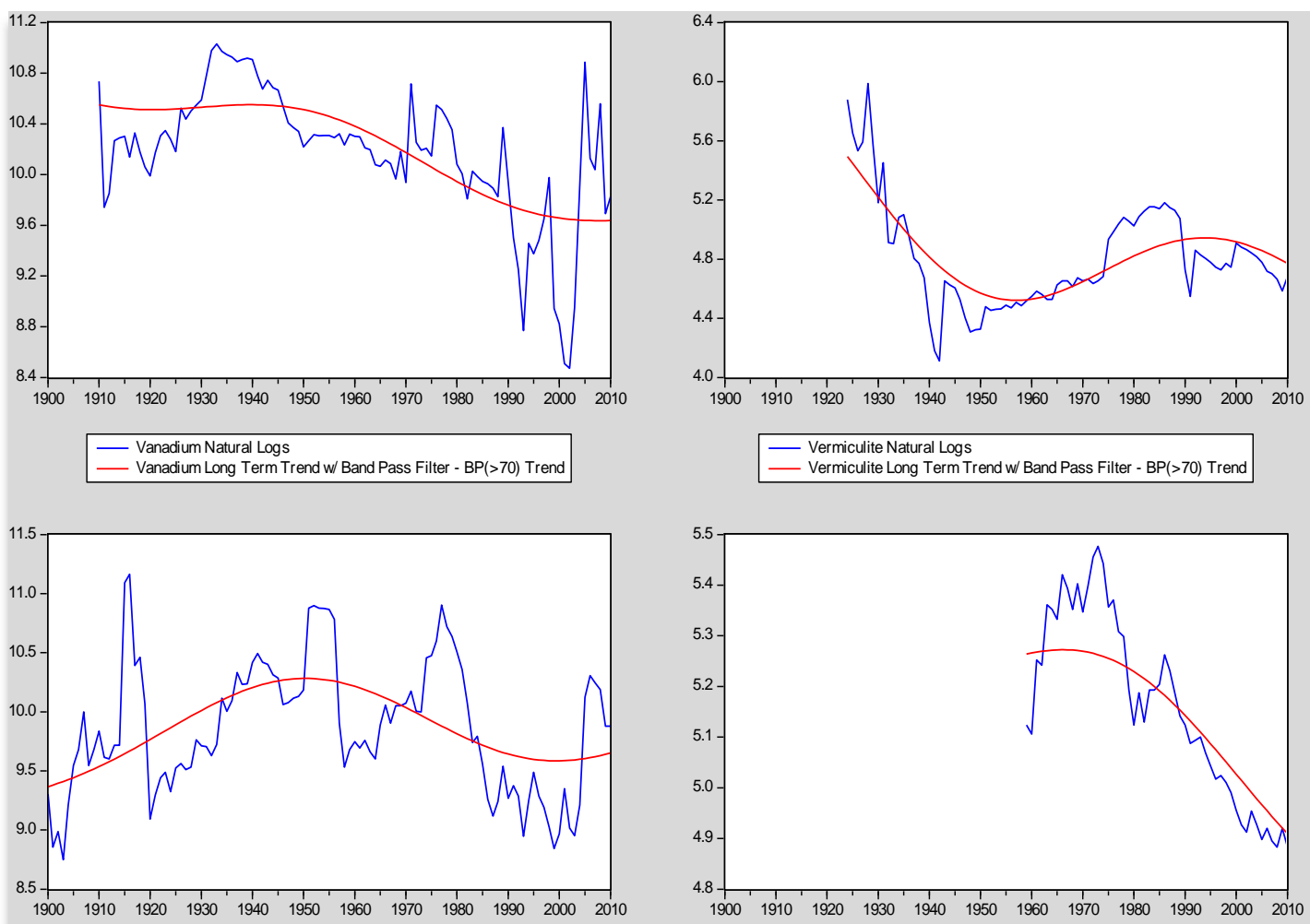

— Tungsten Natural Logs

Tungsten Long Term Trend w/Band Pass Filter - BP( $>70)$ Trend

- Wollastonite Natural Logs

Wollastonite Long Term Trend w/ Band Pass Filter - BP $(>70)$ Trend
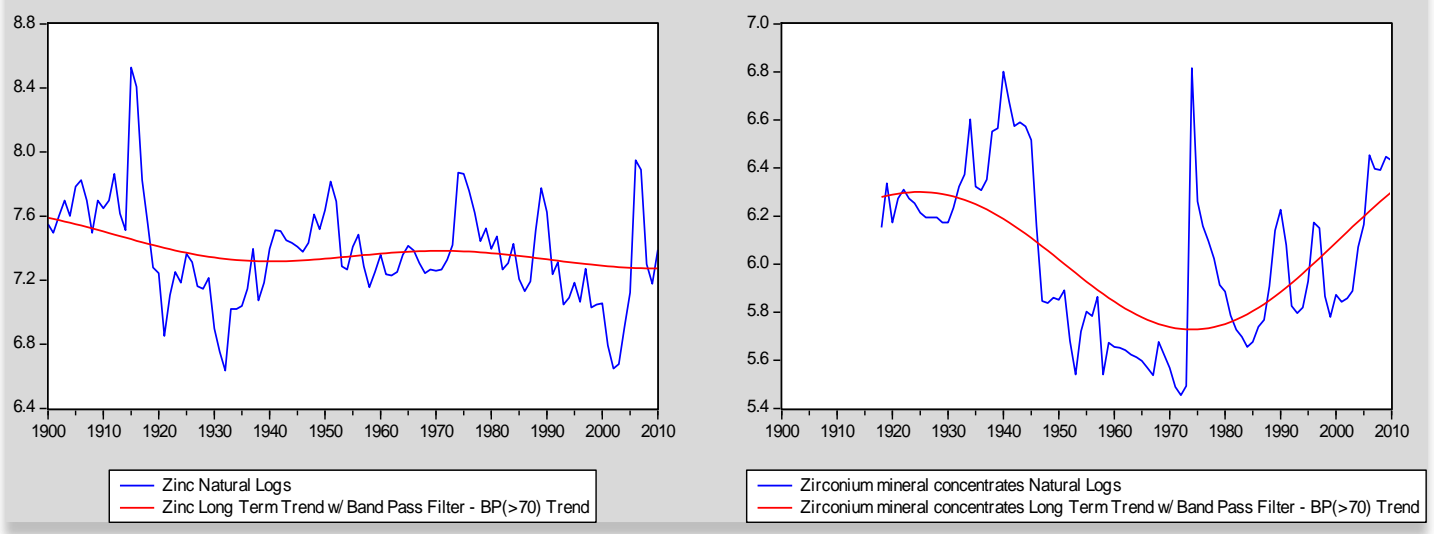